\title{
Diagnostic différentiel des troubles à expression nerveuse dans l'espèce bovine en Europe occidentale
}

\author{
C. Saegerman ${ }^{(1)}$, L. Claes ${ }^{(2)}$, A. Dewaele(3), D. Desmecht ${ }^{(3)}$, F. Rollin ${ }^{(5)}$, \\ J. Hamoir ${ }^{(6)}$, P. Gustin ${ }^{(6)}$, G. Czaplicki ${ }^{(7)}$, J. Bughin ${ }^{(7)}$, J. Wullepit ${ }^{(2)}$, \\ J. Laureyns ${ }^{(8)}, S$. Roels ${ }^{(9)}$, D. Berkvens ${ }^{(10)}$, E. Vanopdenbosch ${ }^{(9)} \&$ E. Thiry ${ }^{(4)}$ \\ (1) Agence fédérale pour la sécurité de la chaîne alimentaire, Administration de la politique de \\ contrôle, World Trade Center III, Boulevard Simon Bolivar 30, B-1000 Bruxelles, Belgique \\ (2) Dierengezondheidszorg Vlaanderen, Kruisstraat 24, B-3061 Leefdaal, Belgique \\ (3) Service de pathologie générale, Faculté de médecine vétérinaire, Université de Liège, Boulevard de \\ Colonster 20 B43, B-4000 Liège, Belgique \\ (4) Service de virologie-épidémiologie, Faculté de médecine vétérinaire, Université de Liège, Boulevard de \\ Colonster 20 B43 bis, B-4000 Liège, Belgique \\ (5) Service de médecine interne des grands animaux, Faculté de médecine vétérinaire, Université de \\ Liège, Boulevard de Colonster 20 B42, B-4000 Liège, Belgique \\ (6) Service de pharmacologie, pharmacothérapie et toxicologie, Faculté de médecine vétérinaire, Université \\ de Liège, Boulevard de Colonster 20 B41, B-4000 Liège, Belgique \\ (7) Association régionale de santé et identification animale, Allée des Artisans 2, B-5590 Ciney, Belgique \\ (8) Dienst van de algemene pathologie, Faculteit Diergeneeskunde, Universiteit van Gent, Salisburylaan 133, \\ B-9820 Merelbeke, Belgique \\ (9) Centre d'étude et de recherches vétérinaires et agrochimiques, Groeselenberg 99, B-1180 Uccle, Belgique \\ (10) Prins Leopold Instituut voor Tropische Geneeskunde, Departement Diergeneeskunde, Nationalestraat 155, \\ B-2000 Antwerpen, Belgique
}

\begin{abstract}
Résumé
Une classification des troubles neurologiques ou à expression nerveuse susceptibles d'être rencontrés en Europe occidentale chez les bovins âgés de 12 mois et plus a été établie selon l'étiologie, la fréquence et les conditions d'apparition, l'âge et le type d'animaux concernés et les principaux signes cliniques observés. Les troubles à expression nerveuse ont été classés selon les différents groupes de causes : biologiques, non biologiques et non spécifiques ou inconnues. Le diagnostic différentiel des troubles à expression nerveuse est un élément essentiel de l'épidémiosurveillance clinique de l'encéphalopathie spongiforme bovine. Un nombre croissant d'étiologies est décrit dans la littérature scientifique. L'identification et la gestion centralisée des troubles neurologiques permettront, d'une part, de tenir compte de la variabilité inhérente à la forme clinique développée et à la démarche diagnostique de l'observateur et, d'autre part, d'identifier de nouveaux facteurs de risque permettant leur maîtrise.

\section{Mots-clés}

Bovin - Cause biologique - Cause non biologique - Cause non spécifique Encéphalopathie spongiforme bovine - Europe - Trouble neurologique.
\end{abstract}

\section{Introduction}

L'incidence des troubles neurologiques chez la bête bovine est peu connue à l'échelle de la population et les résultats disponibles sont peu comparables. Ces données sont pourtant de toute première importance pour l'épidémiosurveillance des encéphalopathies subaiguës spongiformes transmissibles (124). Un pourcentage relatif de $0,82 \%$ de pathologies neurologiques a été mentionné parmi l'ensemble des pathologies rencontrées en pratique vétérinaire (65). En Suisse, lincidence annuelle minimale des cas neurologiques examinés dans les universités 
de Zürich et Berne a été estimée à 89 bovins de tout âge par million d'animaux; ce taux est assez faible (73). Aux États-Unis d'Amérique, le réseau « National Animal Health Monitoring System » (NAHMS) a enregistré, pour l'année 1995, un taux de mortalité d'une vache laitière sur 1000 en raison «d'un manque de coordination motrice et une sévère dépression » et, pour l'année 1996, un taux de morbidité dans les troupeaux viandeux d'une femelle reproductrice présentant des « problèmes neurologiques » sur $1000(29,30)$. D'après Heim et coll. (73), la distribution des pathologies neurologiques concerne préférentiellement les bovins âgés de moins d'un an (29,3\%) et ceux de quatre à cinq ans (18,9\%).

La distinction entre maladies nerveuses et syndromes nerveux n'est pas aisée. En effet, une pathologie comme la babésiose bovine peut aboutir à une anoxie ou un coma hépatique ayant pour conséquence l'apparition de signes cliniques à expression nerveuse. Tsuji et coll. ont reproduit ce phénomène sur un modèle souris (140). L'expression «troubles à expression nerveuse » (TEN) a été utilisée et est définie comme étant : « tout cas neurologique où, soit l'anamnèse et/ou la clinique mentionnent une symptomatologie nerveuse, soit un résultat d'un examen nécropsique et/ou d'un examen complémentaire identifient une cause morbide pouvant induire une symptomatologie nerveuse, soit en l'absence d'un ou de plusieurs éléments qui précèdent, si des analyses ont été réalisées sur le système nerveux central » (124).

Il existe plusieurs critères de classification des TEN en fonction de l'objectif poursuivi. Différentes clefs d'entrée ont été envisagées. Le choix peut porter sur les signes cliniques et leur durée d'évolution $(6,11,17,111,123,128,133,136,154)$, sur l'examen histopathologique de l'encéphale $(73,134)$, sur les examens complémentaires, ceux-ci pouvant être ante mortem $(11,57,58,141)$ ou post mortem $(62,111)$, ou, enfin, sur le résultat d'un traitement $(11,111,144)$. Le diagnostic étiologique des troubles neurologiques est nécessaire également pour identifier des problèmes de troupeau ou des erreurs de conduite d'élevage (6).

Des outils spécialisés d'aide à la décision ont été mis au point au cours de ces dernières années. Les signes cliniques observés lors de l'examen clinique d'un animal peuvent être introduits dans un logiciel qui donne une liste de diagnostics à envisager par ordre alphabétique (155). Plus récemment, des classements probabilistes ont été proposés en tenant compte de 55 pathologies à expression nerveuse présentes au RoyaumeUni (33). Ceux-ci sont basés sur la présence ou l'absence de 14 signes cliniques aisément reconnaissables. Ainsi, les signes évoluant depuis plus de 15 jours, le plus fréquemment rencontrés en cas d'encéphalopathie spongiforme bovine (ESB) sont la crainte et/ou la nervosité, l'hyperesthésie et l'ataxie. Ce profil clinique correspond à celui décrit dans d'autres pays européens $(14,38,85,125,126,131,149,150,153,156)$.

L'objectif poursuivi par cet article est d'établir, chez les bovins âgés de 12 mois et plus, une classification des TEN susceptibles d'être rencontrés en Europe occidentale selon l'étiologie, l'âge, la fréquence, les circonstances d'apparition et les principaux signes cliniques observés. Pour une raison de clarté, les étiologies ont été regroupées par catégories. Les causes biologiques ont été subdivisées en causes parasitaires, mycosiques, bactériennes, virales et agents transmissibles non conventionnels. Les causes non biologiques sont subdivisées en causes mécaniques, physiques, chimiques, métaboliques et nutritionnelles, génétiques et immunes. Enfin une dernière catégorie a été ajoutée. Il s'agit des causes non spécifiques ou inconnues. Le diagnostic différentiel des troubles à expression nerveuse est un élément essentiel de l'épidémiosurveillance clinique de l'ESB (78).

\section{Causes biologiques}

\section{Maladies d'origine parasitaire}

Les TEN d'origine parasitaire (129) sont rencontrés rarement ou occasionnellement chez les bovins en Europe occidentale (Tableau I). Le plus souvent, ils résultent soit d'un traitement inadapté (hypodermose), soit de conditions régionales particulières (babésiose), soit d'erreurs de gestion dans un contexte de surpeuplement (coccidiose), soit enfin du passage d'un agent infectieux chez un hôte intermédiaire (toxoplasmose) (48). Accessoirement, des nématodes (129), des cestodes (56) et des protozoaires (15) peuvent induire des TEN.

\section{Maladies d'origine mycosique}

Certains champignons peuvent parasiter des plantes et produire des mycotoxines trémorgènes (128). Lorsque ces plantes sont distribuées aux bovins, elles peuvent occasionner des TEN (34, 90, 117, 143, 159). L'ergotisme est un exemple bien connu (voir ci-dessous, parmi les causes non biologiques, la section « Causes chimiques »).

\section{Maladies d'origine bactérienne}

Parmi les causes biologiques induisant des TEN, les causes bactériennes ont été les plus fréquentes, après les causes virales, dans les pays où la rage a sévi à l'état enzootique (124). Parmi ces causes bactériennes (Tableau II), viennent en premier lieu : la listériose $(73,79,92,99,136)$; la méningo-encéphalite thrombosante, qui frappe plutôt les jeunes bovins $(134,136)$, l'abcès parahypophysaire $(134,136,144)$, le tétanos $(92,136)$ et le botulisme $(32,68,134,136)$. Les méningites et/ou encéphalites purulentes sont fréquemment la conséquence d'une bactériémie et sont caractérisées par une alternance de signes cliniques correspondant à une période initiale d'excitation, suivis de signes cliniques correspondant à l'arrêt des fonctions $(11,93)$. Par contiguité de tissu, une sinusite (écornage, bris de corne ou de dent) ou une otite peuvent induire des TEN $(70,109)$. L'entérotoxémie, qui est moins fréquemment rencontrée chez le bovin adulte, peut également 
Tableau I

Principales causes parasitaires des troubles d'expression nerveuse en Europe occidentale chez les bovins âgés de plus de 12 mois

\begin{tabular}{|c|c|c|c|c|}
\hline $\begin{array}{l}\text { Affection et } \\
\text { agent causal }\end{array}$ & Fréquence & Âge et type d'animaux & Condition d'apparition et principaux signes cliniques & Références \\
\hline $\begin{array}{l}\text { Hypodermose } \\
\text { Hypoderma bovis }\end{array}$ & + & Animaux de tout âge & $\begin{array}{l}\text { Insecticide systémique administré au moment de la migration larvaire } \\
\text { au niveau du canal rachidien (après la mi-décembre) } \\
\text { Démarche raide, instable puis paralysie }\end{array}$ & 11 \\
\hline $\begin{array}{l}\text { Forme nerveuse } \\
\text { de la coccidiose } \\
\text { Eimeria } s p .\end{array}$ & ++ & Jeunes animaux & $\begin{array}{l}\text { Plus fréquente lors d'un été pluvieux } \\
\text { Animaux en stabulation ou confinés } \\
\text { Forme nerveuse peu rencontrée } \\
\text { Diarrhée fétide, mucoïde et tachée de sang } \\
\text { Tremblements musculaires } \\
\text { Nystagmus } \\
\text { Hyperesthésie } \\
\text { Décubitus avec convulsions } \\
\text { Opisthotonos }\end{array}$ & 6,11 \\
\hline $\begin{array}{l}\text { Forme furieuse } \\
\text { de la babésiose } \\
\text { Babesia divergens }\end{array}$ & ++ & Animaux adultes & $\begin{array}{l}\text { Liée à certaines régions en raison : } \\
\text { - de la présence de tiques } \\
\text { - d'un biotope particulier (haies, buissons) } \\
\text { - de la transmission verticale dans la descendance des tiques } \\
\text { Liée aux bonnes saisons (augmentation de l'activité des tiques) } \\
\text { Le trépied de la symptomatologie est le suivant: } \\
\text { - forte fièvre pouvant aller jusqu'à } 42^{\circ} \mathrm{C} \\
\text { - ictère hémolytique (muqueuses couleur jaune pâle) } \\
\text { - hémoglobinurie (urines couleur « brun chocolat ») } \\
\text { Abattement important (prostration) } \\
\text { Diminution importante de la production lactée } \\
\text { Anémie } \\
\text { Occasionnellement, troubles nerveux dus à l'anoxie et, à l'état chronique, } \\
\text { dus au coma hépatique } \\
\text { - grincement des dents } \\
\text { - incoordination motrice, ataxie } \\
\text { - folie furieuse } \\
\text { - convulsions et coma }\end{array}$ & 1 \\
\hline $\begin{array}{l}\text { Forme nerveuse } \\
\text { de la toxoplasmose } \\
\text { Toxoplasma gondii }\end{array}$ & + & $\begin{array}{l}\text { Les bovins semblent } \\
\text { assez résistants }\end{array}$ & $\begin{array}{l}\text { Encéphalite et pneumonie : } \\
\text { - température } \\
\text { - dyspnée } \\
\text { - ataxie } \\
\text { - hyperexcitation puis léthargie }\end{array}$ & $1,11,48$ \\
\hline
\end{tabular}

+ : rare

++ : rencontré occasionnellement

induire des TEN dans la forme subaiguë (6, 11, 100). L'hydrocéphalie acquise, qui peut être d'origine inflammatoire, est exceptionnelle chez les ruminants et est caractérisée par une immobilité permanente, parfois interrompue par des crises d'excitation $(11,93)$.

Une augmentation significative du nombre de cas de listériose a été constatée en Suisse, en raison d'un tableau clinique et d'une distribution d'âges qui sont proches de ceux de l'ESB (74). La prévalence de la listériose dans les troupeaux laitiers a été estimée à $11,7 \%$ en Angleterre (intervalle de confiance $95 \%$ : 9,6 \%-14,6\%) (53). Dans plusieurs pays, les premiers cas d'ESB ont été diagnostiqués à la suite d'une suspicion de listériose (23). Les résultats d'examens histopathologiques indiquent une augmentation significative de la fréquence de la listériose en hiver et au printemps (126). Cette observation a été rapportée à plusieurs reprises dans la littérature scientifique
$(53,54,73,105,123,154)$. On l'explique par le régime alimentaire, plus particulièrement la consommation d'ensilage mal conservé ou en trop grande quantité $(11,64,105,123)$. La listériose peut induire des toxi-infections alimentaires collectives (130).

\section{Maladies d'origine virale}

En raison d'une enzootie de rage ayant sévi dans plusieurs pays d'Europe occidentale, les causes virales (Tableau III) ont été longtemps les plus fréquentes (124). Dans deux pays au moins, le premier cas d'ESB a été diagnostiqué suite à une suspicion de rage $(74,150)$. La rage doit être envisagée dans le diagnostic différentiel de l'ESB (59), bien que le temps d'évolution soit généralement plus court, c'est-à-dire inférieur à une semaine (151). En Belgique, toutes les suspicions de rage qui sont infirmées sont également analysées pour l'ESB (125, 126, 150). La plupart des pays d'Europe occidentale sont 


\section{Tableau II}

Principales causes bactériennes des troubles d'expression nerveuse en Europe occidentale chez les bovins âgés de plus de 12 mois

\begin{tabular}{|c|c|c|c|c|}
\hline $\begin{array}{l}\text { Affection et } \\
\text { agent causal }\end{array}$ & Eréquence & $\begin{array}{l}\text { Âge et type } \\
\text { d'animaux }\end{array}$ & Condition d'apparition et principaux signes cliniques & Références \\
\hline $\begin{array}{l}\text { Listériose } \\
\text { Listeria monocytogenes }\end{array}$ & ++++ & Animaux adultes & $\begin{array}{l}\text { Surtout en hiver et au printemps } \\
\text { Avortement, mammite, septicémie du veau } \\
\text { Température supérieure à } 40^{\circ} \mathrm{C} \\
\text { Signes cliniques le plus souvent unilatéraux } \\
\text { Paralysie du nerf facial (VII) : } \\
\text { - ptose de I'oreille, de la paupière supérieure et de la lèvre inférieure } \\
\text { - présence d'aliments d'un côté de la bouche } \\
\text { - ptyalisme unilatéral } \\
\text { Paralysie du nerf trijumeau (V) : } \\
\text { - hypoalgésie faciale (répond mal ou pas à une stimulation) } \\
\text { Paralysie du nerf vestibulaire (racine inférieure du nerf auditif VIII) : } \\
\text { - tête déviée d'un côté } \\
\text { - marche tournante (toujours dans le même sens) } \\
\text { Hémiparésie } \\
\text { Phase terminale : décubitus sternal avec persistance du tourner en rond } \\
\text { (disposition circulaire de la litière) } \\
\text { Bonne réponse à une antibiothérapie précoce surtout si l'animal est jeune } \\
\text { (pénicillines ou tétracyclines) }\end{array}$ & $\begin{array}{l}53,54,73 \\
74,79,92 \\
99,105 \\
123,125 \\
136\end{array}$ \\
\hline $\begin{array}{l}\text { Tétanos } \\
\text { Clostridium tetani }\end{array}$ & ++ & Animaux de tout âge & $\begin{array}{l}\text { Origine tellurique } \\
\text { Anamnèse : plaie, écornage, chirurgie, rétention d'arrière-faix } \\
\text { Les germes se multiplient dans les érosions des muqueuses ou les plaies } \\
\text { profondes ou recouvertes (anaérobiose) } \\
\text { Temps d'incubation : } 1 \text { à } 3 \text { semaines, mais peut être plus long } \\
\text { Raideur musculaire généralisée (paralysie spastique bilatérale) : } \\
\text { - gêne à la préhension des aliments et de l'eau } \\
\text { - trismus } \\
\text { - procidence de la troisième paupière } \\
\text { - oreilles raides tirées en arrière } \\
\text { - extension de la tête et de l'encolure (aspect d'un cerf) } \\
\text { - soulèvement de la queue (constant) } \\
\text { - météorisme persistant (non constant) } \\
\text { - absence de toute tendance à se coucher (position en chevalet) } \\
\text { Hyperesthésie au bruit, à la lumière et au toucher } \\
\text { Décubitus latéral au stade final: } \\
\text { - membres en extension spastique } \\
\text { - toute chance de guérison disparaît }\end{array}$ & 92,136 \\
\hline $\begin{array}{l}\text { Botulisme } \\
\text { Clostridium botulinum }\end{array}$ & ++ & Animaux de tout âge & $\begin{array}{l}\text { Le germe se multiplie dans les matières animales en décomposition } \\
\text { (cadavres et leurs restes) } \\
\text { La multiplication de Cl. botulinum est également possible dans les ensilages } \\
\text { d'herbe, surtout si le pH est alcalin, et en conditions d'anaérobiose } \\
\text { Paralysie musculaire flasque, progressive et bilatérale : } \\
\text { a) dans la forme classique (antérieure) } \\
\text { - les oreilles et les paupières supérieures s'affaissent } \\
\text { - la bouche s'ouvre facilement et la langue est pendante } \\
\text { - dysphagie (eau, aliments) } \\
\text { - myosis } \\
\text { b) dans la forme non classique (ascendante) } \\
\text { - la queue est pendante (comme une « balançoire ") } \\
\text { - I'anus ne se contracte plus au fouiller rectal } \\
\text { - démarche vacillante et trébuchante } \\
\text { - parésie de l'arrière-train qui évolue ensuite vers l'avant } \\
\text { - puis décubitus (menton sur le sol, queue allongée en arrière) } \\
\text { Respiration abdominale en phase terminale } \\
\text { Mort en quelques jours suite à une paralysie respiratoire }\end{array}$ & $\begin{array}{l}32,68,134 \\
136\end{array}$ \\
\hline $\begin{array}{l}\text { Méningo-encéphalite } \\
\text { thrombo-embolique } \\
\text { infectieuse } \\
\text { Haemophilis somnus }\end{array}$ & e & Bovins à l'engrais & $\begin{array}{l}\text { Incubation de } 1 \text { à } 4 \text { semaines } \\
\text { Morbidité de } 10 \% \text { et mortalité de } 90 \text { \% } \\
\text { Des troubles respiratoires précèdent les troubles nerveux : toux, jetage, } \\
\text { salivation (pas nécessairement chez les mêmes animaux) } \\
\text { D'abord fièvre élevée (phase septicémique), puis température normale } \\
\text { après quelques heures : ataxie, incoordination locomotrice puis décubitus } \\
\text { La fermeture des paupières est caractéristique mais l'animal voit toujours } \\
\text { Parfois, strabisme unilatéral divergent }\end{array}$ & 134,136 \\
\hline
\end{tabular}


Tableau II (suite)

\begin{tabular}{|c|c|c|c|c|}
\hline $\begin{array}{l}\text { Affection et } \\
\text { agent causal }\end{array}$ & juence & $\begin{array}{l}\text { Âge et type } \\
\text { d'animaux }\end{array}$ & Condition d'apparition et principaux signes cliniques & Références \\
\hline & & & \multicolumn{2}{|l|}{$\begin{array}{l}\text { Forte dépression (apathie malgré forte stimulation auditive ou tactile) } \\
\text { Persistance de la salivation et du jetage } \\
\text { Paralysie de la queue, de l'anus et de la vessie (décelable par fouiller rectal) } \\
\text { La septicémie induit une polyarthrite (grosses articulations) } \\
\text { Évolution vers la mort en quelques heures à trois jours }\end{array}$} \\
\hline $\begin{array}{l}\text { Abcès } \\
\text { parahypophysaire }\end{array}$ & ++ & Animaux de tout âge & $\begin{array}{l}\text { Prédisposition anatomique due à l'important réseau veineux périphérique } \\
\text { Résulte souvent du placement incorrect d'un anneau nasal (nécrose du cartilage } \\
\text { du septum) ou d'une complication d'écornage (sinusite) } \\
\text { Abcès métastatique circonscrit } \\
\text { Paralysie plus ou moins nette de la mâchoire inférieure } \\
\text { La mâchoire tremble et par extension le mufle aussi } \\
\text { Difficulté de déglutition (dysphagie) } \\
\text { Appétit et soif sont conservés mais : } \\
\text { - une partie de l'eau coule hors de la bouche } \\
\text { - lors de la prise de nourriture, constitution d'une chique } \\
\text { Intérêt pour l'environnement conservé ou peu altéré } \\
\text { Traitement sans effet }\end{array}$ & $\begin{array}{l}134,136 \\
144\end{array}$ \\
\hline Sinusite & +++ & Animaux de tout âge & $\begin{array}{l}\text { Par contiguïté de tissu } \\
\text { Suite à un écornage, un bris de corne ou de dent } \\
\text { Fièvre } \\
\text { Dépression } \\
\text { Une ou deux paupières sont gonflées et tombantes } \\
\text { Une conséquence peut être l'induction d'un abcès parahypophysaire }\end{array}$ & 70 \\
\hline Otite & +++ & Jeunes animaux & $\begin{array}{l}\text { Par contiguïté de tissu } \\
\text { Fièvre et dépression } \\
\text { Rotation de la tête vers le bas et du côté atteint } \\
\text { Tendance à tourner en cercle du côté atteint } \\
\text { Une paralysie faciale du côté atteint peut être observée }\end{array}$ & 109 \\
\hline $\begin{array}{l}\text { Entérotoxémie } \\
\text { Clostridium perfringens }\end{array}$ & +++ & $\begin{array}{l}\text { Veaux au pis, } \\
\text { bétail à l'engrais }\end{array}$ & $\begin{array}{l}\text { Souvent suraigu : mort sans signe clinique } \\
\text { Dans la forme subaiguë, les signes cliniques suivants peuvent être observés : } \\
\text { - salivation, coliques } \\
\text { - constipation / diarrhée } \\
\text { - excitation fugace / dépression dominante } \\
\text { - décubitus, mouvements de pédalage } \\
\text { - opisthotonos et coma } \\
\text { Autopsie : entérite segmentaire hémorragique avec fréquemment une adénite satellit }\end{array}$ & $\begin{array}{l}\text { 6, } 11,100 \\
\text { te }\end{array}$ \\
\hline Hydrocéphalie acquise & + & Plus souvent les jeunes & $\begin{array}{l}\text { Rétention et hypersécrétion de liquide céphalo-rachidien résultant le plus souvent } \\
\text { d'une épendymite, d'une méningite ou d'une ventriculite } \\
\text { Qualifiée d'interne quand elle affecte les cavités internes } \\
\text { Qualifiée d'externe quand elle affecte les espaces sous-arachnoïdiens } \\
\text { Engendre une immobilité permanente, rarement entrecoupée d'excitation } \\
\text { Résulte souvent d'une découverte d'autopsie tout en n'étant pas nécessairement } \\
\text { la cause de la mort }\end{array}$ & 11,93 \\
\hline
\end{tabular}

\footnotetext{
+ : rare

++ : rencontré occasionnellement

+++ : rencontré moins fréquemment

++++ : rencontré couramment

* souvent d'origine inflammatoire
} 
Tableau III

Principales causes virales des troubles d'expression nerveuse en Europe occidentale chez les bovins âgés de plus de 12 mois

\begin{tabular}{|c|c|c|c|c|}
\hline $\begin{array}{l}\text { Affection et } \\
\text { agent causal }\end{array}$ & réquence & $\begin{array}{l}\text { Âge et type } \\
\text { d'animaux }\end{array}$ & Condition d'apparition et principaux signes cliniques & Références \\
\hline $\begin{array}{l}\text { Rage } \\
\text { Lyssavirus } \\
\text { Rhabdoviridae }\end{array}$ & ++ & Animaux de tout âge & $\begin{array}{l}\text { La plupart des pays d'Europe occidentale sont actuellement reconnus indemnes } \\
\text { de rage } \\
\text { La période d'incubation varie de } 20 \text { à } 150 \text { jours et plus (en moyenne : } 35 \text { à } 45 \text { jours) } \\
\text { Le temps d'évolution est généralement de } 2 \text { à } 6 \text { jours } \\
\text { Tous les signes cliniques ne sont pas toujours présents } \\
\text { Phase prodromique (quelques heures à quelques jours) : } \\
\text { - anorexie, légère hyperthermie et chute brutale de la lactation } \\
\text { - salivation (bave claire et filante), beuglements rauques et biphasiques } \\
\text { - agressivité (rare chez les bovins), parésie ou paralysie } \\
\text { Phase furieuse : } \\
\text { - modification du comportement avec irritabilité, hyperexcitabilité, ténesme } \\
\text { et beuglements } \\
\text { - ne refuse ni l'eau, ni la nourriture mais la déglutition est impossible } \\
\text { Phase terminale : parésie, paralysie, déshydratation (amaigrissement rapide), } \\
\text { prostration et opisthotonos }\end{array}$ & $1,139,151$ \\
\hline $\begin{array}{l}\text { Maladie d'Aujeszky } \\
\text { Suid herpesvirus } 1 \\
\text { Herpesviridae }\end{array}$ & + & Animaux de tout âge & $\begin{array}{l}\text { Transmission par contact direct ou indirect avec le porc (épandage de lisier, } \\
\text { matériel, personnel) } \\
\text { La transmission aérienne est possible, surtout quand la densité porcine est élevée } \\
\text { La période d'incubation est de } 3 \text { à } 6 \text { jours } \\
\text { L'issue est toujours mortelle (quelques heures ou au maximum } 6 \text { jours) } \\
\text { Le premier signe clinique est le jetage nasal } \\
\text { Après } 2 \text { à } 3 \text { jours, les bovins présentent de la dyspnée, du ptyalisme et du } \\
\text { météorisme } \\
\text { Les animaux boivent beaucoup } \\
\text { Les signes nerveux apparaissent ensuite : } \\
\text { - tremblements musculaires et piétinements } \\
\text { - les bovins se couchent et se lèvent de manière incessante } \\
\text { - ils fouettent de la queue et alternent excitation avec beuglement et dépression } \\
\text { - il n'y a pas d'agressivité } \\
\text { Le signe clinique dominant est le prurit incoercible : } \\
\text { - localisé à certains endroits (mufle, épaules, membres, ventre) } \\
\text { - l'animal malade soulage son prurit jusqu'à l'automutilation, par tous les moyens : } \\
\text { léchage, grattage, frottement } \\
\text { La mortalité conjointe d'un ou de plusieurs chats dans l'exploitation est un indicateur }\end{array}$ & $\begin{array}{l}124,139 \\
160\end{array}$ \\
\hline $\begin{array}{l}\text { Coryza gangreneux }^{(\mathbf{a})} \\
\text { Ovine herpesvirus } 2 \\
\text { Herpesviridae }\end{array}$ & ++ & Animaux adultes & $\begin{array}{l}\text { La forme européenne bovine est associée au mouton } \\
\text { Le mouton est un porteur asymptomatique du virus } \\
\text { La période des agnelages est propice à la dissémination du virus } \\
\text { La transmission horizontale chez les bovins n'est pas décrite } \\
\text { L'incubation dure de quelques semaines à quelques mois } \\
\text { Un syndrome fébrile et une prostration sont marqués } \\
\text { Un enduit nécrotico-fibrineux d'odeur fétide recouvre le mufle } \\
\text { La congestion des vaisseaux est visible (muqueuses rouge brique) } \\
\text { Lésions ulcéro-nécrotiques des muqueuses digestive et nasale } \\
\text { Polyadénomégalie } \\
\text { Lésions cutanées sous forme de croûtes en surélévation } \\
\text { Péricoronarite aiguë ulcéreuse } \\
\text { Diarrhée ou dysenterie } \\
\text { Troubles nerveux rares et inconstants : } \\
\text { - fasciculations musculaires } \\
\text { - incoordination motrice } \\
\text { - nystagmus } \\
\text { - faiblesse générale avec refus de marcher } \\
\text { - grincements des dents }\end{array}$ & $\begin{array}{l}25,37,45 \\
92,127 \\
139\end{array}$ \\
\hline $\begin{array}{l}\text { Diarrhée virale bovine } \\
\text { Pestivirus bovins } \\
\text { Flaviviridae }\end{array}$ & e & $\begin{array}{l}\text { Bovins âgés } \\
\text { de } 6 \text { à } 24 \text { mois }\end{array}$ & $\begin{array}{l}\text { La surinfection exogène ou endogène (mutation) du veau infecté immunotolérant } \\
\text { persistant (IPI) par une souche de virus de la diarrhée virale bovine de biotype } \\
\text { cytopathogène et présentant par ailleurs les mêmes caractéristiques antigéniques } \\
\text { que la souche de biotype non cytopathogène présente chez l'animal IPI, déclenche } \\
\text { la maladie des muqueuses } \\
\text { II n'y a pas de forme nerveuse décrite dans la maladie des muqueuses } \\
\text { Toutefois, des isolements du virus de la diarrhée virale bovine sur des encéphales } \\
\text { de bovins âgés de plus d'un an suspects et infirmés d'encéphalopathie sponfigorme } \\
\text { bovine ont été réalisés }\end{array}$ & 126,139 \\
\hline
\end{tabular}


Tableau III (suite)

\begin{tabular}{|c|c|c|c|c|}
\hline $\begin{array}{l}\text { Affection et } \\
\text { agent causal }\end{array}$ & Eréquence & $\begin{array}{l}\text { Âge et type } \\
\text { d'animaux }\end{array}$ & Condition d'apparition et principaux signes cliniques & Références \\
\hline $\begin{array}{l}\text { Rhinotrachéite } \\
\text { infectieuse bovine } \\
\text { Bovine herpesvirus } 5 \\
\text { (BoHV-5) } \\
\text { Bovine herpesvirus } 1 \\
\text { (BoHV-1) } \\
\text { Herpesviridae }\end{array}$ & + & Plus souvent les jeunes & $\begin{array}{l}\text { Le BoHV-1 est capable de provoquer des encéphalites chez le veau de } 3 \text { à } 8 \text { jours : } \\
\text { - après une phase d'excitation, sans hyperthermie, le veau présente une période } \\
\text { de dépression accompagnée de cécité } \\
\text { - des symptômes respiratoires et généraux sont associés } \\
\text { - la guérison est rare et la mort survient } 3 \text { à } 4 \text { jours après l'apparition des } \\
\text { premiers signes cliniques } \\
\text { - toutefois, des isolements viraux de BoHV-1 sur des encéphales de bovins âgés } \\
\text { de plus d'un an suspects et infirmés d'encéphalopathie sponfigorme bovine } \\
\text { ont été réalisés } \\
\text { Le BoHV-5 provoque des encéphalites chez les jeunes veaux âgés de plus } \\
\text { de } 10 \text { mois: } \\
\text { - l'infection de bovins adultes est possible expérimentalement } \\
\text { - l'infection de bovins par le BoHV-5 est peu connue en Europe occidentale }\end{array}$ & $\begin{array}{l}104,122 \\
126 \\
139,155\end{array}$ \\
\hline $\begin{array}{l}\text { Maladie de Borna } \\
\text { Bornavirus } \\
\text { Bornaviridae }\end{array}$ & + & Animaux adultes & $\begin{array}{l}\text { Maladie plus fréquente chez les chevaux et les moutons } \\
\text { L'infection est fréquemment inapparente chez les bovins } \\
\text { Les signes cliniques apparaissent après une longue période d'incubation sous } \\
\text { la forme d'une encéphalopathie progressive : } \\
\text { - alternance de phases d'excitation et de somnolence } \\
\text { - ataxie, difficulté de proprioception, troubles oculaires } \\
\text { - l'issue fatale survient trois semaines après le début de la phase clinique }\end{array}$ & $\begin{array}{l}12,40,87 \\
96,102 \\
110,139 \\
163\end{array}$ \\
\hline $\begin{array}{l}\text { Leucose bovine } \\
\text { enzootique } \\
\text { Virus de la leucose bovin } \\
\text { Retroviridae }\end{array}$ & ine & Plus souvent les adultes & $\begin{array}{l}\text { De nombreuses infections sont subcliniques } \\
\text { Le diagnostic clinique n'est possible qu'en cas de phase tumorale } \\
\text { Une proportion de 0,1 \% à } 10 \% \text { des bovins infectés développe la phase tumorale, } \\
\text { contrairement aux ovins où tous les individus développent des tumeurs et meurent } \\
\text { dans les } 5 \text { à } 7 \text { années suivant l'inoculation } \\
\text { Dans la majorité des cas, les tumeurs atteignent les ganglions lymphatiques } \\
\text { (un ou plusieurs) et peuvent s'étendre aux organes les plus divers } \\
\text { Les symptômes, s'ils sont visibles, sont la conséquence des phénomènes } \\
\text { compressifs engendrés par les tumeurs }\end{array}$ & 139 \\
\hline $\begin{array}{l}\text { Louping-ill } \\
\text { Virus du louping-ill } \\
\text { Flaviviridae }\end{array}$ & + & Animaux de tout âge & $\begin{array}{l}\text { Affecte principalement le mouton } \\
\text { Transmis par la tique Ixodes ricinus } \\
\text { Infection le plus souvent subclinique } \\
\text { Parmi les animaux infectés, seuls certains présentent des troubles du système } \\
\text { nerveux central caractérisés par de l'ataxie, de la paralysie, du coma et la mort }\end{array}$ & 139 \\
\hline $\begin{array}{l}\text { Immunodéficience } \\
\text { bovine } \\
\text { Lentivirus } \\
\text { Retroviridae }\end{array}$ & $++++^{(b)}$ & Animaux adultes & $\begin{array}{l}\text { La période d'incubation est longue, de } 3 \text { à } 5 \text { ans } \\
\text { Leucocytose } \\
\text { Lymphadénopathie avec hyperplasie folliculaire } \\
\text { Lésions cutanées rebelles au traitement } \\
\text { Méningo-encéphalite }\end{array}$ & $\begin{array}{l}9,18,28 \\
81,132 \\
135,139\end{array}$ \\
\hline
\end{tabular}

$+\quad:$ rare

$+\quad$ : rencontré occasionnellement

++++ : rencontré couramment

a) coryza grangreneux associé au mouton

b) existence de bovins séropositifs dans de nombreux pays ; souches virales isolées en nombre limité

actuellement reconnus indemnes de rage $(112,114)$. On pourrait dès lors penser que la part prise par les causes virales sera moins importante. Toutefois, plusieurs diagnostics étiologiques viraux ont récemment été posés chez des bovins âgés de plus de 12 mois ayant présenté une méningoencéphalite non purulente : le virus de la diarrhée virale bovine chez une bête bovine âgée de 26 mois (126) ; l'herpèsvirus bovin 1 , responsable de la rhinotrachéite infectieuse bovine chez une bête bovine âgée de 44 mois (122, 126); et l'herpèsvirus ovin 2, responsable du coryza gangreneux, chez trois bovins âgés de 12 à 18 mois, dont deux avaient eu des contacts avec des moutons (45). Des épidémies d'encéphalite à herpèsvirus bovin 5 ont été principalement décrites en
Australie, en Argentine, au Brésil et aux États-Unis d'Amérique. Le virus a été identifié en Hongrie et en Allemagne. Cependant, de nombreuses souches d'herpèsvirus isolées de cas cliniques d'encéphalite bovine n'ont pas été caractérisées. Il est probable que la distribution de l'infection à herpèsvirus bovin 5 est plus étendue que les résultats d’isolement ne le laissent présager (104, 139). Les signes cliniques de coryza gangreneux sont dominés par un syndrome fébrile marqué, des lésions oculaires de kératoconjonctivite et d'uvéite, des lésions ulcéronécrotiques des muqueuses digestive et nasale et une polyadénomégalie $(25,127)$. Une péricoronarite aiguë ulcéreuse a également été observée (45). Les signes cliniques nerveux sont inconstants (127), rares et consistent souvent en des fasciculations 
musculaires $(25,37,127)$, une incoordination motrice (37) et du nystagmus (25). Une faiblesse générale avec refus de marcher et des grincements des dents ont également été décrits chez les bovins (45).

La maladie de Borna est rare chez les bovins, contrairement aux chevaux et aux moutons $(96,139)$. Toutefois, le virus de la maladie de Borna a été mis en évidence chez des bovins en bonne santé en Allemagne (87, 102, 163), en Suisse (27) et au Japon (71). Plus récemment, la maladie de Borna a été diagnostiquée chez des bovins ayant présenté des TEN dans plusieurs pays : en Allemagne (12), en Suisse (26), en France (40) et au Japon (110). Le tableau clinique ressemble partiellement à l'ESB (96). Par ailleurs, la détection d'anticorps, d'antigènes et/ou du génome viral dans le tissu nerveux d'humains décédés et ayant présenté des troubles psychiatriques sévères, a relancé le débat d'une possible implication de ce virus dans l'étiologie d'affections neurologiques et sur l'hypothèse d'une éventuelle transmission de ce virus de l'animal à l'homme $(40,96,139)$.

Le virus du louping-ill est transmis par la tique Ixodes ricinus. L'infection est le plus souvent subclinique. Parmi les animaux infectés, seuls certains présentent des troubles du système nerveux central caractérisés par de l'ataxie, de la paralysie, du coma et la mort (139).

La leucose bovine enzootique peut induire des TEN. Plusieurs pays d'Europe occidentale sont reconnus officiellement indemnes de leucose bovine enzootique par la Commission européenne (36). La vigilance portera sur les animaux importés de pays non encore reconnus comme officiellement indemnes. Enfin, les bovins en contact avec des porcins peuvent contracter la maladie d'Aujeszky $(119,124,139,160)$. Ce risque diminuera au cours du temps, en raison des plans de qualification des troupeaux porcins et d'une nécessaire séparation stricte des unités de production. Toutefois, des cas sporadiques pourraient persister par le biais de contacts avec des sangliers sauvages, comme cela a déjà été démontré pour le chien de chasse en Allemagne (8).

Le rétrovirus de l'immunodéficience bovine (BIV) appartient au genre Lentivirus ; la période d'incubation est de trois à cinq ans (139). Des bovins séropositifs ont été retrouvés dans tous les pays examinés $(28,81,118,132)$. De la leucocytose, de la lymphadénopathie, de la méningo-encéphalite et des lésions rebelles au traitement sont retrouvées chez les bovins infectés naturellement ou expérimentalement $(9,18,135,139,152)$.

\section{Agents transmissibles non conventionnels}

Les agents transmissibles non conventionnels ont été provisoirement classés parmi les causes biologiques. Depuis sa première description clinique en 1986 (153), l'ESB a affecté un grand nombre de pays européens $(49,67,75,115,150,156$,
157). La maladie affecte les bovins adultes, avec un pic de fréquence situé à 4-5 ans (156). A ce jour, le plus jeune bovin atteint cliniquement d'ESB était âgé de 20 mois et le plus vieux était âgé de 19 ans et 9 mois (44). La durée de la maladie clinique, depuis les signes cliniques les plus précoces jusqu'à la mort ou la mise à mort, peut être inférieure à deux semaines $(85,98,125,154)$ ou se prolonger jusqu'à une année (85). La durée moyenne est d'un ou deux mois environ (85). La fréquence des signes cliniques neurologiques observés chez 164771 bovins atteints d'ESB a été déterminée par Wilesmith (156). Dans plus de $50 \%$ des cas, on observe les troubles et les anomalies suivants :

a) troubles psychiques: crainte, modification du tempérament, position anormale des oreilles et comportement anormal ;

b) troubles de la sensibilité : réponse exagérée aux stimuli, léchage excessif;

c) anomalie de la posture et des mouvements : ataxie et tremblements.

Une grande majorité d'animaux malades présentent des signes cliniques entrant dans ces trois catégories. De plus, certains signes généraux peuvent être associés à l'ESB : altération de l'état général, amaigrissement et une diminution de la production laitière. Des variations considérables dans la présence et la gravité des signes cliniques pris individuellement ont été constatées. Si les animaux sont maintenus dans un environnement calme et familier, la gravité des signes cliniques, particulièrement l'hyperesthésie, est diminuée. Après quelques semaines, les signes cliniques conduisent progressivement à des chutes répétées, puis à un décubitus permanent et enfin à la mort (85).

La détection de l'ESB repose sur l'observation des signes cliniques (156) et/ou nécessite une surveillance active basée sur la mise en évidence de la protéine prion anormale $\mathrm{PrP}^{\mathrm{sc}}$ par des tests immunologiques rapides effectués sur des prélèvements réalisés au niveau du système nerveux central des animaux et ce, post mortem ou lors de l'abattage (107, 108, 115). Le diagnostic de confirmation repose sur un examen histologique du système nerveux central démontrant l'aspect spongiforme de l'encéphale, sur l'extraction et l'examen des fibrilles associées à la scrapie ou examen SAF (scrapie associated fibrils), sur l'immunocytochimie ou sur le western-blot (85, 156).

Le nouveau variant de la maladie de Creutzfeldt-Jakob (vCJD) a été identifié pour la première fois au Royaume-Uni en 1996 (158). Ultérieurement, il a été montré que la souche de l'agent pathogène responsable du vCJD est très semblable à celle de l'agent de l'ESB $(19,77)$. Plusieurs revues ont été rédigées sur le sujet (par exemple 162). 


\section{Causes non biologiques}

\section{Causes mécaniques}

La probabilité de l'occurrence des causes mécaniques augmente avec l'âge des animaux. Les pathologies traumatiques du système nerveux sont relativement rares chez les animaux de rente (73), sauf chez les animaux lourds, pour lesquels les chevauchements et les chutes sont plus dommageables (46). Les problèmes vasculaires ne sont généralement pas observés chez l'animal (73). Les fractures du crâne ou du rachis, les (sub)luxations et les compressions médullaires se caractérisent le plus souvent par une hyperesthésie du segment se trouvant juste avant le siège de la lésion, une parésie ou une paralysie et une insensibilité en arrière du siège de la lésion. Les accidents peripartum proviennent soit de la surcharge pondérale induisant un traumatisme des vertèbres lombo-sacrées, des lésions occasionnées à la filière pelvienne lors du part (parésie ou paralysie du part) ou, plus fréquemment, d'une ischémie résultant d'un décubitus prolongé (paraplégie postpartum). La spondylose ossifiante peut être observée chez des taureaux âgés et lourds (6). Une douleur intense consécutive à un corps étranger peut également induire des TEN.

Les pathologies nerveuses néoplasiques chez les bovins sont rares $(55,73,99,161)$. La durée de vie plus brève des bovins dans les conditions actuelles peut être une explication. En France, sur la base d'enquêtes réalisées à l'abattoir, leur fréquence a été estimée entre 0,1 et 10 tumeurs par million d'animaux (69). En Belgique, dans le cadre du réseau d'épidémiosurveillance de l'ESB, sur un total de 375 examens histopathologiques réalisés en 1998 et 1999, seul un neuroblastome cérébelleux a été identifié $(125,126)$.

\section{Causes physiques}

Les causes physiques sont assez rares. L'insolation ou le coup de chaleur trouvent leur place ici parce qu'ils entraînent fréquemment un œedème cérébral (93). Ils affectent plus souvent les jeunes animaux en raison du rapport élevé entre la surface corporelle et le poids. Des animaux plus âgés et gras, et des animaux confinés (transport) ou insuffisamment abreuvés peuvent cependant aussi être concernés par ces pathologies. La fulguration ou l'électrocution conduisent à un choc nerveux se traduisant le plus souvent par la mort immédiate ou, occasionnellement, par une perte de conscience temporaire, suivie ou non de séquelles nerveuses (11).

\section{Causes chimiques}

Les causes chimiques occupent historiquement la deuxième position parmi les causes non biologiques des TEN en Europe occidentale (124). La gamme potentielle des toxiques présents dans l'environnement des ruminants adultes est grande (31, 43). Les cas d'intoxication semblent être plus fréquents au printemps et en été, en raison des traitements phytosanitaires et de la mise en pâture des bovins (43). En outre, la curiosité naturelle, l'habitude de lécher et le fort appétit, parfois peu sélectif, des bovins en font des cibles privilégiées $(6,20)$. Les intoxications d'origine chimique les plus courantes induisant des TEN englobent les intoxications par le sel (régions maritimes), le plomb, les organophosphorés et les carbamates, ainsi que par certains végétaux. L'importance relative d'un certain nombre de toxiques tels que les métaux lourds et les métalloïdes, mais aussi d'autres toxiques industriels ou non industriels (plomb, arsenic, mercure, strychnine et cyanures) a tendance à régresser, du fait d'une meilleure information et prévention. Néanmoins, des intoxications ponctuelles par certains polluants ne pourront jamais être écartées et peuvent avoir de graves répercussions économiques, médicales ou sociales. Celles-ci doivent donc faire l'objet d'une attention toute particulière, afin de minimiser les risques encourus par les animaux de rente et donc par le consommateur. L'intoxication par le plomb (saturnisme) reste l'une des plus fréquentes (5, 43). Le saturnisme aigu est caractérisé par de l'amaurose, du pousser au mur et de la cécité, ce qui se traduit chez les bovins par la position de « radar» des oreilles, des errances et de l'incoordination motrice accompagnée de dépression ou de convulsion. De la diarrhée ou de la constipation, de l'arumination et du tympanisme peuvent aussi être observés. Une mastication «à vide» s'accompagnant d'une salivation spumeuse est un signe très suggestif et a valu au saturnisme le nom de «maladie du mâchonnement». L'intoxication chronique est quant à elle caractérisée par de l'anorexie, un arrêt de la rumination, du météorisme, une inhibition de la croissance, une dégradation de l'état général ainsi qu'une anémie légère à modérée, accompagnée d'une augmentation de la protoporphyrinémie (136). Des avortements et du jetage peuvent aussi être observés. Les intoxications par des biocides sont devenues moins fréquentes chez les bovins, du fait de l'utilisation plus rationnelle de ces produits (120, 137). Néanmoins, certaines races de ruminants telle que la race charolaise semblent être plus sensibles à une intoxication par les organophosphorés ou carbamates (95). Les signes cliniques observés dans ce cas sont attribuables à une inhibition d'estérases. Cette inhibition aboutit à une combinaison variable de signes muscariniques (vomissement, diarrhée, salivation, incontinence urinaire, lacrymation, bronchoconstriction, tympanisme, myosis, bradycardie), nicotiniques (tremblements, convulsions, parésie et paralysie) et nerveux centraux, plus tardifs et moins souvent observés (hyperexcitabilité, dépression, prostration, coma). L'utilisation médicale des organochlorés a été fortement limitée puisque la commercialisation et l'emploi du lindane comme seul principe actif ont été interdits. Des spécialités à usage auriculaire enregistrées pour certains animaux de compagnie en contiennent encore. Son emploi toujours effectif en agriculture peut donner lieu, lors de contact ou d'ingestion, à des intoxications cliniques. Dans ce cas, le tableau clinique est dominé par de l'agitation, des fasciculations musculaires, de l'ataxie, des convulsions et de l'hyperthermie (22). 
Les intoxications par les chlorates, les nitrates ou lors d'exposition chronique au cuivre (surtout chez le jeune veau) sont responsables d'une élévation du taux de méthémoglobine, entrainant une diminution de l'oxygénation cellulaire. Une cyanose, un sang noirâtre peu coagulable et une tachycardie de compensation sont observés et sont accompagnés de somnolence, de dyspnée (11). La mort est constatée lorsque le taux de méthémoglobinémie atteint ou dépasse $80 \%$. Les chlorates constituent un herbicide total relativement peu toxique pour les bovins (22), mais sont très appétants et peuvent par conséquent être consommés en quantité importante (42). Quant aux intoxications par le métaldéhyde, molluscicide très courant, elles sont beaucoup moins fréquentes chez la bête bovine (20) que chez les carnivores domestiques qui sont souvent enclins à consommer des appâts préparés à des fins criminelles. Dans ce cas, les ruminants atteints présentent des troubles digestifs (salivation, diarrhée) et nerveux (tremblements musculaires, convulsions, ataxie). Une cécité peut être observée (22).

Les nitrates, transformés en nitrites plus toxiques dans le rumen, peuvent parfois être rendus responsables d'intoxications suite à l'ingestion de plantes telles que le colza, les choux, les betteraves, les navets, le ray-grass, devenues trop riches en nitrates en raison de diverses circonstances environnementales ou climatiques défavorables, comme l'humidité et le gel précoce $(43,80,95)$. L'utilisation excessive d'engrais, d'herbicides phénoxy-acides et la pollution des eaux peuvent aussi être des intervenants non négligeables dans ce type d'intoxication. Comme les chlorates, la toxicité des nitrites est liée à son action irritante pour les muqueuses et méthémoglobinisante (62).

Un grand nombre de végétaux contenant des substances toxiques se retrouvent dans la nature $(20,41)$. La fréquence respective de chacun d'entre eux dépend du biotope rencontré. Sauf exception (par exemple Atropa belladonna), seul un traitement symptomatique peut être tenté face à une intoxication végétale (22). Si l'animal meurt, une autopsie et une détermination des restes de végétaux contenus dans le rumen ou retrouvés sur le terrain seront utiles pour identifier le risque et éviter de nouveaux cas (43). Lors de litige juridique, comme par exemple lors de dépôts de taille de haies sur une pâture par un voisin, une identification botanique des végétaux déposés sur la pâture pourrait être jugée insuffisante et doit donc être accompagnée d'une identification botanique et/ou chimique sur l'animal. Certains de ces végétaux toxiques peuvent être rencontrés dans les campagnes et peuvent induire des TEN. Une énumération non exhaustive inclut : l'if (intoxication subaiguë par Taxus baccata) $(22,124)$, de nombreuses plantes cyanogènes (laurier cerise, sureau, lin, sorgho) (20, 22), les glands de chêne (95), le ray-grass quand celui-ci est parasité par Neotyphodium ou Acremonium (10, 34), le seigle quand celui-ci est parasité par Claviceps purpurea (ergotisme) (11, 62, 94), la grande ciguë (6), le buis, le thuya, la morelle noire, la belladone, l'oenanthe safranée, le rhododendron, l'azalée et le cytise (20).
En raison d'une sécurité accrue, les intoxications médicamenteuses sont devenues plus rares. Elles se rencontrent lors de surdosage, d'un mauvais usage des médicaments, d'utilisation de préparations non autorisées ou d'une sensibilité particulière liée à la race ou lâge. Les principaux principes actifs dont l'usage nécessite une attention particulière sont les suivants: les quinolones (148), les nitrofuranes qui sont interdits d'utilisation $(2,35,137)$, les sulfamidés (62), la lincomycine qui peut induire une acétonémie $(11,121)$, les aminosides (11, 39), mais aussi certains antiparasitaires, antiprotozoaires ou anthelminthiques comme les dérivés d'avermectines et de milbémycines tels que la moxidectine (observations cliniques non publiées), les salicylanilidés pouvant entraîner de la cécité (11, 147), l'amprolium (146), le lévamisole/tétramisole (47) et les organophosphorés.

\section{Causes métaboliques et nutritionnelles}

Les affections métaboliques (88) sont des troubles fonctionnels ne s'accompagnant généralement pas de lésion des tissus nerveux $(6,103)$. Elles représentent un grand problème chez les bovins (73) et leur fréquence relative est la plus élevée parmi les causes non biologiques induisant des TEN (124). Étant donné que la mortalité est relativement basse et que dans beaucoup de cas, cause et thérapie sont connues, seuls $17 \%$ des cas sont référés (73). Du fait des modifications précoces de comportement, les pathologies métaboliques et nutritionnelles (Tableau IV) interviennent dans le diagnostic différentiel de l'ESB $(73,83,85,131)$. Une durée d'évolution insidieuse et une récidive à un traitement doivent faire suspecter l'ESB. La nécrose du cortex cérébral est une maladie métabolique à caractère sporadique (élevage traditionnel) ou enzootique (par exemple chez des bovins à l'engrais). Elle est due à une perturbation de la synthèse ruménale de la vitamine B1, à une destruction de la vitamine $\mathrm{B} 1$ par des thiaminases, ou à un excès de soufre dans la ration. Elle touche le plus souvent des animaux âgés de plus de 4 mois (rumen fonctionnel) à moins de 24 mois $(73,92)$. Des cas sont décrits également chez des animaux plus âgés (73). Une cécité d'origine centrale est observée. Suite à limportante augmentation des pressions intra-crânienne et intra-rachidienne, l'animal élève la tête en extension. Lorsqu'il est encore capable de marcher, il adopte un pas de parade, tourne en rond en longeant les parois. Une ataxie et une incoordination motrice croissante s'installent peu avant le décubitus (136).

\section{Causes génétiques}

Les affections d'origine génétique dans l'espèce bovine sont nombreuses et variées $(6,62)$. La sélection intensive des reproducteurs à l'intérieur d'un petit pool de sujets d'élite augmente la diversité et la fréquence des troubles de cette nature $(6,138)$. Généralement, les animaux atteints d'anomalies sont morts ou euthanasiés avant lâge de 12 mois $(73,91,134)$. L'ataxie progressive des bovins charolais $(6,62)$ a été décrite chez des bovins de 8 à 24 mois. La spasticité 
Tableau IV

Principales causes métaboliques et nutritionnelles des troubles d'expression nerveuse en Europe occidentale chez les bovins âgés de plus de 12 mois

\begin{tabular}{|c|c|c|c|}
\hline Fréquence & $\begin{array}{l}\text { Âge et type } \\
\text { d'animaux }\end{array}$ & Condition d'apparition et principaux signes cliniques & Références \\
\hline $\begin{array}{l}\text { Fièvre du lait } \\
\text { Hypocalcémie puerpérale } \\
\text { Fièvre vitulaire }\end{array}$ & $\begin{array}{l}\text { Surtout les vaches } \\
\text { laitières }\end{array}$ & $\begin{array}{l}\text { Lors de la période péri-partum (en particulier les premières semaines post-partum) } \\
\text { L'incidence estimée est de } 5 \text { à } 6 \text { vaches pour } 100 \text { vaches par année à risque } \\
\text { L'affection représente } 70 \% \text { à } 80 \% \text { des vaches couchées }\end{array}$ & $\begin{array}{l}3,6,11,61 \\
66,88,89 \\
155\end{array}$ \\
\hline
\end{tabular}

Fièvre vitulaire

Parésie puerpérale

Cause : excès de cations en période de tarissement

On décrit classiquement trois stades

Stade 1 : I'animal est capable de se lever et de rester debout

- le pis est tendu en l'absence de mammite

- une excitation initiale et des spasmes tétaniques peuvent être aperçus

Stade 2 : décubitus sternal en auto-auscultation le plus souvent (tête dans le flanc)

- avec anorexie, atonie du rumen et absence de défécation

- puis il y a engourdissement (extrémités froides) et atténuation des réflexes

- les yeux sont tristes, fixes et les pupilles sont dilatées (mydriase)

Stade 3 : le décubitus devient latéral avec perte de conscience, coma et mort

La réponse à la calcithérapie est généralement bonne (l'éructation est le premier signe d'amélioration

Certaines fièvres de lait nécessitent l'apport de potassium et de vitamine D

\section{Tétanie d'herbage $\quad++\quad$ Génisses ou vaches \\ Hypomagnésiémie}

Toxémie de gestation

de la vache viandeuse

\section{Urémie}

Insuffisance rénale
$++$

Animaux de tout âge

bovin viandeux

en malnutrition protéocalorique
Excès d'azote non protéique

Alcalose du rumen Intoxication à l'urée
Surtout chez les génisses ou les vaches en lactation

Aussi chez des vaches hautes productrices en fin de tarissement

Ou chez des vaches après un très long transport ou un stress

Plus fréquente au printemps et en automne lors de consommation d'herbe jeune ou de second cycle, ou d'herbe sur laquelle une grande quantité d'engrais a été épandu (potasse et azote sous forme de nitrate d'ammonium)

Yeux exorbités, grincements des dents

Excitation, hyperesthésie, mouvements des oreilles vers I'arrière

Fasciculations musculaires (épaules, cuisses), tétanie

Hyperthermie inconstante (surtout observée au moment des crises)

Mort soudaine ou convulsions

Réponse à la magnésiothérapie mais des échecs sont fréquents

Le dosage de la fraction du magnésium urinaire est un moyen de diagnostic précoce

Le dosage de magnésium peut être réalisé dans I'humeur aqueuse jusque $48 \mathrm{~h}$ après la mort (si la température extérieure $<23^{\circ} \mathrm{C}$ )

Du début de lactation jusqu'au pic de lactation

Elle est primaire lorsque la balance énergétique est négative (déséquilibre entre les apports et les besoins)

Elle est secondaire quand l'appétit diminue suite à une autre maladie (boiterie, mammite, déplacement de caillette)

Baisse de la production laitière

D'abord l'appétit est capricieux : les concentrés et les ensilages sont délaissés

Puis amaigrissement rapide et durable

pas de température

Les symptômes nerveux sont inconstants, généralement tardifs et intermittents :

- léchage incessant, mastication et salivation

- incoordination, mouvements en cercle, pousser au mur

- parfois, tremblements, tétanie, délire passager

Une odeur d'acétone peut être décelée dans l'air expiré, dans les urines et le lait Les corps cétoniques peuvent être aisément dosés dans l'urine, le lait et le sang La vache malade guérit dans $80 \%$ des cas

Stade terminal de l'insuffisance rénale ou inflammation rénale aiguë ou chronique $\quad 11,88,155$ Température normale, ou augmentée si l'origine est inflammatoire

Déshydratation, anorexie, faiblesse

Tachypnée et tachycardie

Des troubles à expression nerveuse sont rapportés :

- dépression

- tremblements musculaires, piétinement continuel

Souvent il s'agit d'une série clinique

La cause d'intoxication est un excès d'azote non protéique (ANP) dans la ration,

dû à :

- un excès d'apport (vaches laitières) ou le passage brutal à un apport d'ANP

- un système de distribution d'ANP défectueux (vaches laitières)

- une ingestion accidentelle d'engrais azotés
$6,11,88$,

89,97 ,

101, 155

52, 76, 88 ,

89,155

11, 62,

106,116 .

155 
Tableau IV (suite)

\begin{tabular}{lll}
\hline Affection & Fréquence & $\begin{array}{l}\text { Âge et type } \\
\text { d'animaux }\end{array}$ \\
\hline
\end{tabular}

- une accumulation d'ANP dans l'herbe lors d'utilisation de grandes quantités d'engrais ou lorsque le temps devient subitement froid (perturbation de la synthèse des protéines)

Un délai de 3 à 4 semaines est nécessaire pour adapter la microflore ruménale du bétail de telle sorte qu'elle puisse utiliser des quantités progressivement augmentées d'ANP. Toutefois, I'adaptation est perdue rapidement (après 1 à 3 jours) Après ingestion, I'ANP est hydrolysé et absorbé s'il est en excès par rapport aux squelettes hydrocarbonés disponibles dans le rumen. II induit une hyperammoniémie si le foie est dépassé dans son rôle de synthèse de l'urée Évolution le plus souvent suraiguë $(<4$ heures)

Anorexie, chute brutale de la lactation

Piétinement continuel (membres postérieurs), dos voussé (douleur abdominale)

Ramollissement des excréments (effet de I'ANP sur les muqueuses digestives)

Quelques tremblements et salivation mousseuse

La vache se couche difficilement puis ne se relève plus

Hyporéflexie, opisthotonos en phase terminale

Autopsie : pétéchies myocardiques, l'instestin grêle est très congestionné avec des suffusions sous-muqueuses

Traitement : eau froide (dilution et diminution de l'activité de l'uréase bactérienne) et vinaigre (diminution du $\mathrm{pH}$ ) $\begin{aligned} & \text { Acidose lactique } \\ & \text { aiguë du rumen }\end{aligned} \quad+++\quad$ Animaux de tout âge

Encéphalose hépatique + Hépatose

\section{Photosensibilisation}

Animaux de tout âge avec peau non pigmentée et/ou faiblement recouverte de poil
Importance de l'anamnèse : animal détaché se gavant d'amidon ou de sucres solubles en grande quantité sans transition alimentaire (par exemple : fruits, céréales, betteraves, racines de carottes, chicons [endives], pommes de terre) ou erreur de programmation de la distribution automatisée des concentrés Anorexie, faiblesse, fatigue, dépression Hyperpnée, tachycardie

Atonie du rumen (météorisation) avec liquéfaction de son contenu (aspect laiteux) Diarrhée (matières fécales jaunâtres et mousseuses), déshydratation Tremblements, démarche ébrieuse Décubitus sternal

On peut observer des signes nerveux associés à des affections hépatiques d'origine toxique (mycotoxines, plantes hépatotoxiques, alcaloïdes de la pyrrolizidine du séneçon, cuivre) ou lors de parasitoses hépatiques chroniques importantes (distomatose)

De nombreux facteurs explicatifs des troubles nerveux sont incriminés (par exemple : les troubles du métabolisme protéique avec hyperammoniémie) Apathie, dépression, léthargie Troubles du comportement : hallucinations, accès furieux Convulsions et coma Les enzymes SGOT, SGPT, phosphatase alcaline, SDH sont fortement augmentées Les protéines totales sont diminuées

Les peaux les moins colorées et les plus exposées (dos) sont les plus sensibles Les ultra-violets sont toujours nécessaires pour activer les agents photodynamiques ; la lumière du jour suffit mais la pathologie est surtout rencontrée par temps ensoleillé Cette activation des agents photodynamiques produit de l'énergie et occasionne des lésions cutanées

La photosensibilisaton est primaire quand elle est d'origine exogène :

- par I'alimentation ou par contact

- agents photodynamiques végétaux (séneçon, sarrasin, certaines variétés de trèfles et de luzerne) ou médicamenteux (phénothiazine, sulfamidés, tétracycline)

La photosensibilisation est secondaire quand elle est d'origine hépatogène ; la phylloérythrine dérive de la lyse anaérobie de la chlorophylle par les micro-organismes du rumen. Elle est absorbée normalement dans la circulation sanguine et ensuite éliminée par la voie hépato-biliaire. Toute altération de l'excrétion biliaire (fasciolose étendue, toxiques hépatiques) entraîne son accumulation dans la circulation et peut alors atteindre la circulation périphérique en concentration adéquate pour induire une photosensibilisation

L'apparition d'un cas unique doit faire suspecter la fasciolose hépatique Hyperesthésie des endroits dépigmentés atteints

Fdème, exsudat, nécrose et gangrène des endroits exposés selon le stade d'évolution : surtout la tête (mufle, pourtour des yeux), les trayons et la vulve (œdème asymétrique) L'animal recherche l'ombre en pâture (la mise à l'étable fait partie intégrante du traitement) Des signes à expression nerveuse accompagnent les troubles cutanés : état de prostration intense dû à la douleur ou hyperexcitabilité 
Tableau IV (suite)

\begin{tabular}{|c|c|c|c|c|}
\hline Affection & réquence & $\begin{array}{l}\text { Âge et type } \\
\text { d'animaux }\end{array}$ & Condition d'apparition et principaux signes cliniques & Références \\
\hline $\begin{array}{l}\text { Intoxication au sel } \\
\text { ou à l'eau }\end{array}$ & + & Animaux de tout âge & $\begin{array}{l}\text { Apport normal en sel avec abreuvement insuffisant ou nul, suivi d'un abreuvement } \\
\text { libre (gel des abreuvoirs) ou ingestion d'eau de mer ou alimentation trop salée } \\
\text { Les vaches laitières en haute production sont physiologiquement plus sensibles } \\
\text { Induit un œdème cérébral } \\
\text { Intoxication aiguë : } \\
\text { - diarrhée muqueuse, polyurie } \\
\text { - nystagmus, cécité, opisthotonos } \\
\text { - tremblements, parésie } \\
\text { - décubitus avec convulsions } \\
\text { - mort } 24 \text { h à } 48 \text { h après les premiers signes cliniques } \\
\text { Intoxication chronique : } \\
\text { - inappétence, perte de poids, déshydratation } \\
\text { - faiblesse, diarrhée } \\
\text { - collapsus et convulsions tétaniques à l'effort }\end{array}$ & $6,11,88$ \\
\hline $\begin{array}{l}\text { Nécrose du cortex } \\
\text { cérébral } \\
\text { NCC }\end{array}$ & +++ & $\begin{array}{l}\text { Surtout animaux } \\
\text { âgés de } 4 \text { à } 24 \text { mois }\end{array}$ & $\begin{array}{l}\text { Se raréfie du fait d'une meilleure information } \\
\text { Est due à un trouble du métabolisme de la vitamine B1 : } \\
\text { - soit par carence de production par la flore du rumen } \\
\text { - soit par manque de résorption } \\
\text { - soit en présence de thiaminases (aliments, dérivés de la pipérazine) } \\
\text { Des modifications de la flore du rumen perturbent la production de vitamine B1 : } \\
\text { - changement d'alimentation } \\
\text { - interruption passagère de l'abreuvement } \\
\text { Pas de température } \\
\text { Isolement du reste du troupeau } \\
\text { Cécité d'origine centrale : } \\
\text { - de jour comme de nuit } \\
\text { - absence du réflexe palpébral et présence du réflexe pupillaire (contrairement } \\
\text { au dernier stade de la carence en vitamine A) } \\
\text { - I'animal butte contre les obstacles, il tourne en rond en longeant les parois du } \\
\text { boxe (disposition circulaire de la litière) } \\
\text { Strabisme dorso-médial } \\
\text { L'animal élève la tête en extension suite à l'augmentation des pressions } \\
\text { intra-crânienne et intra-rachidienne (maladie de l'astronome) } \\
\text { Lorsqu'il est encore capable de marcher, il adopte un pas de parade } \\
\text { II perd l'intérêt pour le milieu environnant } \\
\text { Décubitus sternal ou latéral avec mouvements de pédalage et opisthotonos } \\
\text { Évolution vers la mort en } 3 \text { à } 10 \text { jours } \\
\text { Bonne réponse à l'administration de vitamine B1 lors de traitement précoce }\end{array}$ & $\begin{array}{l}6,73,92 \\
128,136\end{array}$ \\
\hline Carence en vitamine $\mathbf{A}$ & A ++ & Surtout les jeunes & $\begin{array}{l}\text { Alimentation carencée en vitamine A de façon prolongée et non complémentée } \\
\text { avec un complexe minéral vitaminé (ensilage de maïs, pulpes séchées, céréales, } \\
\text { tourteaux de lin) } \\
\text { Perte de la vision crépusculaire au stade précoce } \\
\text { Disparition du réflexe palpébral et du réflexe pupillaire contrairement à la NCC } \\
\text { Troubles nerveux très fréquents : convulsions puis paralysie }\end{array}$ & $6,11,88$ \\
\hline $\begin{array}{l}\text { Carence en vitamine } \mathbf{E} \\
\text { Sélénium }\end{array}$ & E +++ & Surtout les jeunes & $\begin{array}{l}\text { Généralement, la myopathie-dyspnée est rencontrée chez les jeunes animaux } \\
\text { mais peut également être observée chez des animaux plus âgés } \\
\text { Parésie spastique }\end{array}$ & 11,145 \\
\hline
\end{tabular}

périodique affecte des bovins âgés de 3 à 7 ans $(6,11)$, tandis que l'épilepsie idiopathique affecte généralement des bovins de moins de deux ans (11). La mannosidose $(7,21,51)$ et la myélo-encéphalopathie dégénérative progressive bovine, appelée encore syndrome de Weaver, affectent essentiellement des bovins âgés de moins d'un an mais ont déjà été observées chez des animaux plus âgés (13, 50, 91, 113, 138). De la cécité a été observée chez un bovin de race Devon âgé de 14 mois qui présentait une lipofuchsinose neuroviscérale $(11,72)$.

\section{Causes immunes}

Parmi les causes immunes, les allergies médicamenteuses sont les plus fréquentes. Celles-ci ont tendance à se raréfier en raison de la production de vaccins en culture cellulaire en lieu et place d'œufs embryonnés. Les accidents observés ont un caractère aigu, sont peu spécifiques et à expression clinique très variable. De l'incoordination motrice peut être observée (4). 


\section{Causes non spécifiques ou inconnues}

En raison du fait qu'un diagnostic étiologique n'est pas toujours demandé car onéreux, un grand pourcentage des TEN sont d'origine inconnue. Ce pourcentage a été estimé à $39 \%$ des animaux suspects de rage en Suisse (54) et historiquement à $40 \%$ des bovins pour lesquels des troubles neurologiques ont été rapportés dans un laboratoire de diagnostic vétérinaire en Belgique (124). Il est probable que certains cas sans altération pathologique étaient de nature métabolico-toxique, comme cela avait été proposé par McGill et Wells (99). Comme l'indiquent les statistiques de l'Institut de neurologie animale de l'université de Berne, le pourcentage relatif de cas sans diagnostic a diminué au cours du temps, du fait de l'expérience acquise et du recours à des techniques d'examen amélioré (73). Plusieurs entités d'origine inconnue ont été décrites dans le cadre du diagnostic différentiel de l'ESB : des convulsions épileptiformes chez des bovins adultes (16, 93), une chromatolyse neuronale et une nécrose des noyaux du tronc cérébral, accompagnée ou non d'une sclérose de l'hippocampe chez des bovins âgés de 6 à 16 ans (82).

\section{Discussion et conclusions}

Une classification des TEN susceptibles d'être rencontrés en Europe occidentale chez les bovins âgés de 12 mois et plus a été établie selon l'étiologie, la fréquence, l'âge et le type d'animaux concernés, les conditions d'apparition et les principaux signes cliniques observés. Les TEN d'incidence rare sont plus fréquemment décrits dans la littérature scientifique de par leur caractère original. Il a également été tenu compte de l'expérience acquise par la profession vétérinaire. Pour ce faire, un tableau préliminaire avait été diffusé à un cercle restreint de vétérinaires praticiens et de laboratoires de diagnostic ayant une motivation particulière sur le sujet, pour qu'ils l'utilisent et le critiquent sur la base de leur activité quotidienne. Cette classification constitue également une aide pour le médecin vétérinaire praticien placé devant un tableau susceptible de générer un diagnostic différentiel qui inclut l'ESB. Pas moins de 85 étiologies pouvant induire des TEN ont été recensées. D'autres classifications sont disponibles en fonction de l'approche utilisée, comme par exemple celle des diagnostics anatomo-pathologiques (73).

L'expression clinique des TEN chez un animal est fonction de plusieurs paramètres: la nature de l'agent causal (dose, virulence) (130), la localisation des lésions occasionnées (63, 111), l'hôte (résistance, état général, statut immunitaire) et l'environnement; certains signes cliniques peuvent être exacerbés lorsque l'environnement de l'animal est modifié (85, 125). La qualité d'observation intervient en premier lieu et est proportionnelle au niveau d'information, de sensibilisation et de formation des éleveurs et des vétérinaires. L'intensité d'observation des animaux joue également un rôle et semble directement proportionnelle à la taille du troupeau. En effet, en référence au réseau NAHMS, le taux d'atteinte de troubles neurologiques d'une vache viandeuse sur 1000 est doublé lorsque la taille du troupeau est inférieure à 100 bêtes et elle est nulle lorsque la taille du troupeau est supérieure à 300 bêtes (30). Tenant compte de ces paramètres, il subsiste toujours une variabilité qui dépend de l'animal et de l'observateur (tableau clinique, phase pré-patente, durée d'évolution). Pour améliorer les connaissances concernant les TEN, il convient :

a) d'améliorer la sensibilisation, l'information et la formation des éleveurs et des vétérinaires,

b) d'utiliser une méthode uniforme d'examen clinique,

c) de recourir plus systématiquement à des examens complémentaires,

d) de former des réseaux sentinelles d'éleveurs et de vétérinaires parmi les plus motivés,

e) de transcrire les résultats des observations sous une forme codifiée et standardisée, tant sur le plan de la nature que de la durée,

f) de rassembler les informations,

g) d'enrichir une base de données relationnelles,

h) de discuter les expériences vécues.

Une typologie des troubles neurologiques pourra alors être établie et des facteurs de risque mis en évidence.

Ce type de réseau a été initié durant l'année 2000, respectivement sur les bovins âgés de plus de 12 mois en Belgique (L. Xambeu, communication personnelle), et sur les bovins âgés de plus de 18 mois en France (24). La pérennité de tels réseaux dépendra du degré de participation volontaire des éleveurs et des médecins vétérinaires, du degré d'analyse des données qui en sera faite et du degré de rétroaction positive (diffusion de rapports synthétiques et spécialisés entre les acteurs des réseaux). Les pathologies neurologiques dans la pratique vétérinaire sont rares (65) et leur diagnostic étiologique est rarement obtenu (58), demande du temps et est relativement coûteux (6). Pour disposer d'une meilleure connaissance en la matière, il convient d'assurer un financement externe pour les charges liées aux investigations d'un diagnostic étiologique. Cette connaissance est, et restera, particulièrement utile en matière d'encéphalopathies subaiguës spongiformes transmissibles, puisqu'elle permettra, d'une part, de retirer les animaux contaminés de la chaîne alimentaire et, d'autre part, de tenir compte du polymorphisme de l'expression clinique. Par ailleurs, dans l'hypothèse d'un passage interespèce des encéphalopathies subaiguës spongiformes 
transmissibles, le temps d'incubation et le tableau clinique pourraient être modifiés, voire atténués (60). Par analogie, il est connu que les ruminants sauvages en captivité atteints d'ESB présentent des signes cliniques similaires, mais la durée d'évolution de la maladie est plus courte, de l'ordre de quelques jours (86). Dès lors, le développement des connaissances concernant les troubles neurologiques et le renforcement des réseaux d'épidémiosurveillance et d'épidémiovigilance existant dans les différents pays sont des priorités.

Pour poser un diagnostic étiologique, il est nécessaire de procéder à un examen clinique selon une méthodologie standardisée, de transmettre une anamnèse complète et de recourir à des examens complémentaires adéquats. Malgré les grands progrès accomplis dans le domaine de la neurologie vétérinaire, des lacunes subsistent dans le relevé et l'analyse systématique des données. Il est regrettable qu'en raison de la difficulté de récolte des anamnèses, l'établissement d'un diagnostic et la réalisation d'enquêtes épidémiologiques soient rendus difficiles $(6,73)$. Poser un diagnostic étiologique est utile, pour plusieurs raisons :

a) classer les pathologies en fonction de leur fréquence d'apparition, et partant, accorder toute l'importance voulue à celles qui sont le plus fréquemment rencontrées (mise en évidence de facteurs de risque permettant leur maîtrise),

b) mettre à jour de nouvelles pathologies pour mieux les comprendre,

c) évaluer la pertinence du diagnostic clinique posé afin d'améliorer la méthodologie de l'approche clinique utilisée. consistent en des troubles psychiques (crainte, modification du tempérament, position anormale des oreilles et comportement anormal) ; des troubles de la sensibilité (réponse exagérée aux stimuli, léchage excessif) et des anomalies de la posture et des mouvements (ataxie et tremblements). L'identification de ceuxci nécessite une démarche clinique (examen méthodique de l'animal au licol et en mouvement dans un environnement inhabituel). Aucun signe clinique n'étant pathognomonique, il est dangereux de ne considérer qu'une seule étiologie lors de l'apparition de signe(s) clinique(s) neurologique(s) chez un animal. La connaissance des éléments de diagnostic différentiel des troubles à expression nerveuse contribue à une meilleure épidémiosurveillance clinique de l'ESB.

\section{Remerciements}

Ce travail a été réalisé en collaboration avec les laboratoires belges de diagnostic vétérinaire et des médecins vétérinaires praticiens. Il a été supporté par les membres du groupe belge d'avis scientifiques relatifs aux encéphalopathies subaiguës spongiformes transmissibles créé sous l'égide du ministère des Classes moyennes et de l'Agriculture.

Les médecins vétérinaires suivants sont vivement remerciés pour leur contribution active à l'élaboration de ce document : G. Andrieu, G. Bertels, G. Boone, D. Cassart, F. Coignoul, A. Delaunois, L. De Meulemeester, R. Danvoye, A. Didier, J. Dufey, D. Lecomte, L. Lecomte, J.-M. Lecomte, B. Limbourg ( $\dagger$ ), B. Losson, E. Myten, F. Moreau, P. Mullier, C. Manteca, B. Sustronck, M. Persyn, J.-M. Robijns, M. Van Aert et G. Vermeiren.

L'ESB est une maladie neurodégénérative. La présence de signes cliniques semble liée à la localisation et au degré de vacuolisation des neurones. Les principaux signes d'appel

\title{
Diagnóstico diferencial de los trastornos con manifestaciones neurológicas de los bovinos en Europa occidental
}

\author{
C. Saegerman, L. Claes, A. Dewaele, D. Desmecht, F. Rollin, J. Hamoir, \\ P. Gustin, G. Czaplicki, J. Bughin, J. Wullepit, J. Laureyns, S. Roels, \\ D. Berkvens, E. Vanopdenbosch \& E. Thiry
}

\section{Resumen}

Se ha procedido a una clasificación de los trastornos neurológicos o con manifestaciones neurológicas que pueden observarse en Europa occidental en los bovinos de 12 meses de edad y mayores, tomando en consideración la etiología, la frecuencia y las condiciones de aparición, la edad y el tipo de animales afectados y los principales signos clínicos observados. Los trastornos 
con manifestaciones neurológicas han sido clasificados por grupos de causas: biológicas, no biológicas y no específicas o desconocidas. El diagnóstico diferencial de los trastornos con manifestaciones neurológicas es un elemento esencial de la vigilancia epidemiológica y clínica de la encefalopatía espongiforme bovina. Las etiologías descritas en las publicaciones científicas son cada vez más numerosas. La identificación y la gestión centralizada de los trastornos neurológicos permitirán tener en cuenta, por un lado, la variabilidad asociada a cada forma clínica y al método de diagnóstico utilizado por el observador, e identificar, por otro lado, nuevos factores de riesgo que permitan su control.

\section{Palabras clave}

Bovino - Causa biológica - Causa no biológica - Causa no específica - Encefalopatía espongiforme bovina - Europa - Trastorno neurológico.

\section{Bibliographie}

1. Acha P.N. \& Szyfres B. (1989). - Zoonoses et maladies transmissibles communes à l'homme et aux animaux, $2^{e}$ éd. Office international des épizooties, Paris, 1063 pp.

2. Ali B.H. (1983). - Some pharmacological and toxicological properties of furazolidone. Vet. Res. Commun., 6, 1-11.

3. Andresen U., Kietzmann M. \& Andresen P. (1999). - Efficacy and tolerance of a calcium-magnesium-aspartate solution in the treatment of hypocalcemic parturient paresis in cows. Berl. Münch. tierärztl. Wochenschr., 112, 400-406.

4. Anon. (1996). - Pharmacovigilantie: anaphylaxie bij runderen. Onverenigbaarheid tussen vaccins en antibiotica: mogelijke aanleiding tot ernstige shockreacties. [Pharmacovigilance. Anaphylaxie chez les bovins, incompatibilité entre les vaccins et les antibiotiques: raison possible d'une réaction de shock sévère.] Communiqué de presse de Mycofarm, Boehringer, Pfizer et Vétoquinol. Mycofarm, Turnhout, 3 pp.

5. Baker J.C. (1987). - Lead poisoning in cattle. Vet. Clin. N. Am. (Food Anim. Pract.), 3, 137-147.

6. Barlow R. (1989). - Differential diagnosis of neurological disorders in cattle. In Practice, 11, 64-73.

7. Barlow R., Mackellar A., Newlands G., Wiseman A. \& Berrett S. (1981). - Mannosidosis in Aberdeen Angus cattle in Britain. Vet. Rec., 109, 441-445.

8. Bastian S., Buffereau J.-P., Le Dream E., Bind J.-L., Müller T. \& Toma B. (2000). - La maladie d'Aujeszky en France. Épidémiol. Santé anim., 38, 109-114.
9. Belloc C., Polack B., Schwartz-Cornil I., Brownlie J. \& Levy D. (1996). - Bovine immunodeficiency virus: facts and questions. Vet. Res., 27, 395-402.

10. Berry P.H., Howell J.M., Cool R.D., Richards R.B. \& Peet R.L. (1980). - Central nervous system changes in sheep and cattle affected with natural or experimental annual ryegrass toxicity. Aust. vet. J., 56, 402-403.

11. Blood E.C. \& Radostits O.M. (1989). - Diseases of the nervous system. In Veterinary Medicine, $7^{\mathrm{e}}$ éd. Baillière Tindall, Londres, 410-448.

12. Bode L., Dürrwald R. \& Ludwig H. (1994). - Borna virus infections in cattle associated with fatal neurological disease. Vet. Rec., 135, 283-284.

13. Braun U., Ehrensperger F. \& Bracher V. (1987). - The Weaver syndrome in cattle. Clinical, biochemical and pathologicoanatomic studies in a Braunvieh/Brown Swiss cow with bovine progressive degenerative myeloencephalopathy. Tierärztl. Praxis, 15, 139-144.

14. Braun U., Schicker E. \& Hornlimann B. (1998). - Diagnostic reliability of clinical signs in cows with suspected bovine spongiform encephalopathy. Vet. Rec., 143, 101-105.

15. Braun U., Rogg E., Walser M., Nehrbass D., Guscetti F., Mathis A. \& Delplazes P. (2002). - Trypanosoma theileri in the cerebrospinal fluid and brain of a heifer with suppurative meningoencephalitis. Vet. Rec., 150, 18-19.

16. Braun U., Schweizer G. \& Hilbe M. (2002). - Epileptiform convulsions in a cow with degeneration of the hippocampus. Vet. Rec., 150, 281-282. 
17. Brewer B.D. (1987). - Examination of the bovine nervous system. Vet. Clin. N. Am. (Food Anim. Pract.), 3, 13-24.

18. Brownlie J., Collins M.E. \& Heaton P. (1994). - Bovine immunodefiency-like virus: a potentiel cause of disease of cattle? Vet. Rec., 134, 289-291.

19. Bruce M.E., Will R.G., Ironside J.W., McConnell I., Drummond D., Suttie A., McCardle L., Chree A., Hope J., Birkett C., Cousens S., Fraser H. \& Bostock C.J. (1997). Transmissions to mice indicate that 'new variant' CJD is caused by the BSE agent. Nature, 389, 498-501.

20. Bruneton J. (1996). - Plantes toxiques. Végétaux dangereux pour l'homme et les animaux. Lavoisier, Paris, 509 pp.

21. Bryan L., Schmutz S., Hodges S.D. \& Snyder F.F. (1990). Bovine beta-mannosidase deficiency. Biochem. Biophys. Res. Commun., 173, 491-495.

22. Buronfosse F., Pineau X. \& Alves de Oliveira L. (2000). - Les principales intoxications. In Maladies des bovins (Institut de l'élevage, dir.). France Agricole, Paris, 216-223.

23. Cachin M., Vandevelde M. \& Zurbriggen A. (1991). - A case of spongiform encephalopathy ('cattle madness') in a cow in Switzerland. Schweizer Arch. Tierheilkd., 133, 53-57.

24. Calavas D., Desjouis G., Collin E., Schelcher F, Philippe S. \& Savey M. (2001). - Incidence et typologie des maladies des bovins adultes à expression nerveuse en France. Épidémiol. Santé anim., 39, 121-129.

25. Callis J.J., Dardiri A.H., Ferris D.H., Gay J.G., Mason J. \& Wilder F.W. (1985). - Manuel illustré sur certaines maladies contagieuses des animaux domestiques. Commission mexicano-américaine pour la prévention de la fièvre aphteuse, Mexico, 27-31.

26. Caplazi P., Waldvogel A., Stitz L., Braun U. \& Ehrensperger F. (1994). - Borna disease in naturally infected cattle. J. comp. Pathol., 111, 65-72.

27. Caplazi P., Melzer K., Goetzmann R., Rohner-Cotti A., Bracher V., Zlinszky K. \& Ehrensperger F. (1999). - Borna disease in Switzerland and in the principality of Liechtenstein. Schweizer Arch. Tierheilkd., 141, 521-527.

28. Cavirani S., Donofrio G., Chiocco D., Foni E., Martelli P., Allegri G., Cabassi C.S., De Iaco B. \& Flammini C.F. (1998). Seroprevalence to bovine immunodeficiency virus and lack of association with leukocyte counts in Italian dairy cattle. Prev. vet. Med., 37, 147-157.

29. Centers for Epidemiology and Animal Health (CEAH) (1996). - National Animal Health Monitoring System. Dairy'96, Part I: Reference of 1996 dairy management practices. United States Department of Agriculture, Fort Collins, 41 pp.
30. Centers for Epidemiology and Animal Health (CEAH) (1997). - National Animal Health Monitoring System. Beef'97, Part II: Reference of 1997 beef cow-calf health and health management practices. United States Department of Agriculture, Fort Collins, 38 pp.

31. Centre d'informations vétérinaires en pharmaco-toxicologie (CIVPT) (2000). - Analyses toxicologiques. CIVPT, faculté de médecine vétérinaire de l'université de Liège (www.ulg.ac.be/fmv/civpt.htm, consulté le 13 décembre 2002).

32. Cobb S.P., Hogg R.A., Challoner D.J., Brett M.M., Livesey R.T., Sharpe R.T. \& Jones T.O. (2002). - Suspected botulism in dairy cows and its implications for the safety of human food. Vet. Rec., 150, 5-8.

33. Cockcroft P.D. (1999). - Pattern-matching models for the differential diagnosis of bovine spongiform encephalopathy. Vet. Rec., 144, 607-610.

34. Colin E. (1998). - Intoxication d'un cheptel bovin par une mycotoxine endophyte : observation d'un cas de rye-grassstagger. Point vét., 29, 1157-1159.

35. Commission européenne (1999). - Règlement 508/1999/CEE du 4 mars 1999 de la Commission modifiant les annexes I à IV du règlement 2377/1990/CEE du Conseil établissant une procédure communautaire pour la fixation des limites maximales de résidus de médicaments vétérinaires dans les aliments d'origine animale. J. off. Communautés eur., L 60, 9 mars, 16-52.

36. Commission européenne (1999). - Décision 1999/465/CE de la Commission du 13 juillet 1999 établissant le statut d'officiellement indemne de leucose bovine enzootique des troupeaux bovins de certains États membres ou régions d'États membres. J. off. Communautés eur., L 181, 16 juillet, 32-33.

37. Cortez P.P., Dias Pereida P., Cortez A. \& Thompson G. (2001). - First confirmed case of malignant catarrhal fever in a cow in Portugal. Vet. Rec., 149, 558-559.

38. Coudert M., Belli P., Savey M. \& Martel J.L. (1995). - Le réseau national d'épidémiosurveillance de l'encéphalopathie spongiforme bovine. Épidémiol. Santé anim., 27, 59-67.

39. Crowell W.A., Divers T.J., Marshall A.E., Nusbaum K.E. \& Larsen L. (1981). - Neomycin toxicosis in calves. Am. J. vet. Res., 42, 29.

40. Dauphin G., Legay V., Sailleau C., Smondack S., Hammoumi S. \& Zientara S. (2001). - Evidence of Borna disease virus genome detection in French domestic animals and in foxes. J. gen. Virol., 82, 2199-2204.

41. Delaunois A. (1998). - Le rôle du médecin vétérinaire dans l'évaluation du risque toxicologique. Ann. Méd. vét., 142, 307-317. 
42. Delaunois A., Gustin P. \& Ansay M. (1992). - Toxicité des herbicides chez les animaux domestiques. Ann. Méd. vét., 136, 181-192.

43. Delaunois A., Bloden S. \& Gustin P. (1999). - Premier bilan d'activités du centre d'informations vétérinaires en pharmacotoxicologie. Ann. Méd. vét., 143, 191-202.

44. Department for Environment, Food \& Rural Affairs (DEFRA) (2002). - Bovine spongiform encephalopathy in Great Britain - Monthly statistics - Youngest and oldest cases by year of onset (passive surveillance only). Document du 30 juin 2002. DEFRA, Londres (www.defra.gov.uk/animalh/bse-statistics/

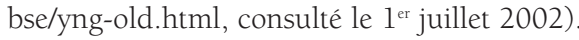

45. Desmecht D., Cassart D., Rollin F., Coignoul F. \& Tham D.-M. (1999). - Molecular and clinicopathological diagnosis of nonwildebeest associated malignant catarrhal fever in Belgium. Vet. Rec., 144, 388.

46. Dive M. (2001). - Rusticité : l'opinion d’un vétérinaire praticien. Elevages belges, 4, 25-26.

47. Donev B., Stoianov K., Dzhurov A. \& Dulev M. (1982). Toxicity of 'Farmakhim' tetramisole in laboratory and farm animals. Vet. Med. Nauki, 19, 70-78.

48. Dubey J.-P. (1986). - A review of toxoplasmosis in cattle. Vet. Parasitol., 22, 177-202.

49. Ducrot Ch., Calavas D., Morignat E., Vinard J.L., Coudert M. \& Savey M. (2001). - Surveillance et épidémiologie de l'ESB en France. Analyse de la situation en mai 2001. Épidémiol. Santé anim., 40, 15-22.

50. El Hamidi M., Leipold H.W. \& Cook J.E. (1990). Ultrastructural changes in Brown Swiss cattle affected with bovine progressive degenerative myeloencephalopathy (Weaver syndrome). Zentralbl. Veterinärmed., A, 37, 729-736.

51. Embury D.H. \& Jerrett I.V. (1985). - Mannosidosis in Galloway calves. Vet. Pathol., 22, 548-551.

52. Enjalabert F., Nicot M.C., Bayrouthe C. \& Moncoulon R. (2000). - Ketone bodies in milk and blood of dairy cows: relationship between concentrations and utilization for detection of subclinical ketosis. J. Dairy Sci., 84, 583-589.

53. Erdogan H.M., Cetinkaya B., Green L.E., Cripps P.J. \& Morgan K.L. (2001). - Prevalence, incidence, signs and treatment of clinical listeriosis in dairy cattle in England. Vet. Rec., 149, 289-293.

54. Fatzer R. \& Steck F. (1974). - Histologische differentialdiagnose bei tollwurverdächtigen rindem. Schweizer Arch. Tierheilkd., 116, 347-356.

55. Fatzer R. \& Fankhauser R. (1977). - Beiträge zur Neuropathologie der Wiederkäuer. II. Neoplasmen. Schweizer Arch. Tierheilkd., 119, 67-78.
56. Fatzer R., Vandevelde M. \& Gottstein B. (2002). - Cerebral taeniid oncospheral lesions in two BSE suspects. Vet. Rec., $150,46-47$

57. Ferrouillet C., Fecteau G. \& Lanevschi A. (1998). Prélèvement et analyse du liquide céphalo-rachidien chez les bovins. Point vét., 194, 15-20.

58. Ferrouillet C., Fecteau G., Higgins R. \& Lanevschi A. (1998). - Analyse du liquide céphalo-rachidien pour le diagnostic des atteintes du système nerveux des bovins. Point vét., 194, 21-26.

59. Foley G.L. \& Zachary J.F. (1995). - Rabies-induced spongiform change and encephalitis in a heifer. Vet. Pathol., 32, 309-311

60. Foster J.D., Parnham D., Chong A., Goldmann W. \& Hunter N. (2001). - Clinical signs, histopathology and genetics of experimental transmission of BSE and natural scrapie to sheep and goats. Vet. Rec., 148, 165-171.

61. Fourichon C., Beaudeau F., Bareille N. \& Seegers H. (2001). Incidence of health disorders in dairy farming systems in western France. Livest. Prod. Sci., 68, 157-170.

62. Fraser C.M., Bergeron J.A., Mays A. \& Aiello S.E. (édit.) (1996). - Système nerveux. In Manuel vétérinaire Merck, $1^{e}$ éd. Éditions d’Après, Paris, 486-541.

63. George L.W. (1996). - Localization and differentiation of neurologic diseases. In Large animal internal medicine, $2^{e}$ éd. Mosby-Year Book, Saint-Louis, 142-170.

64. George L.W. (1996). - Diseases of the nervous system. In Large animal internal medicine, $2^{e}$ éd. Mosby-Year Book, Saint-Louis, 1001-1176.

65. Gerweck G. (1993). - Ein Beitrag zur Krankheisstatistik in der Rinderpraxis. Tierärztl. Umsch., 48, 95-97.

66. Goff J.P. \& Horst R.L. (1997). - Physiological changes at parturition and their relationship to metabolic disorders. J. Dairy Sci., 80, 1260-1268.

67. Gouello L. (1991). - Analyse épidémiologique du premier cas d'encéphalopathie spongiforme bovine en France. Épidémiol. Santé anim., 19, 63-70.

68. Gourreau J.-M. (2000). - Le botulisme. In Maladies des bovins (Institut de l'élevage, dir.). France Agricole, Paris, 80-81.

69. Gourreau J.-M. (2000). - Les affections néoplasiques. In Maladies des bovins (Institut de l'élevage, dir.). France Agricole, Paris, 396-401.

70. Haffar Z. (2000). - L'écornage des bovins. In Maladies des bovins (Institut de l'élevage, dir.). France Agricole, Paris, 480481. 
71. Hagiwara K., Nakaya T., Nakamura Y., Ashi S., Takahashi H., Ishibar C. \& Ikuta K. (1996). - Borna disease virus RNA in peripheral blood mononuclear cells obtained from healthy dairy cattle. Med. Microbiol. Immunol., 185, 145-151.

72. Harper P.A., Walker K.H., Healy P.J., Hartley W.J., Gibson A.J. \& Smith J.S. (1988). - Neurovisceral ceroid-lipofuscinosis in blind Devon cattle. Acta neuropathol. (Berl.), 75, 632-636.

73. Heim D., Fatzer R., Hornlimann B. \& Vandevelde M. (1997). - Häufigkeit neurologischer Erkrankungen beim Rind. Schweizer Arch. Tierheilkd., 139, 354-362.

74. Heim D. \& Kihm U. (1999). - Bovine spongiform encephalopathy in Switzerland - the past and the present. In Gestion des urgences zoosanitaires (G. Murray \& P.M. Thornber, édit.). Rev. sci. tech. Off. int. Epiz., 18 (1), 135-144.

75. Heim D., Detwiler L., Williams E. \& Kihm U. (2001). - Mise à jour sur l'encéphalopathie spongiforme bovine, la tremblante du mouton et la cachexie chronique. In $69^{e}$ Session générale du Comité international de l'Office international des épizooties (OIE), 27 mai-1 ${ }^{\text {er }}$ juin, Paris. Document 69 SG/12/CS3 C, OIE, Paris, 16 pp.

76. Herdt T.H. (2000), - Ruminant adaptation to negative energy balance, influences on the etiology of ketosis and fatty liver. Vet. Clin. N. Am. (Food Anim. Pract.), 16, 215-230.

77. Hill A.F., Desbruslais M., Joiner S., Sidle K.C.L., Gowland J., Collinge L., Doey L.J. \& Lantos P. (1997). - The same prion strain causes vCJD and BSE. Nature, 389, 448-450.

78. Hill F. (1994). - Neurological diseases of cattle where BSE has been included in the differential diagnosis. Surveillance, 21,25 .

79. Hirsbrunner G., Nicolet J., Tontis A. \& Martig J. (1997). Cerebral listeriosis in cattle: literature review and retrospective analysis of individual cases. Tierärztl. Praxis, 25, 336-343.

80. Horner R.F. (1982). - Suspected ammonium nitrate fertiliser poisoning in cattle. Vet. Rec., 110, 472-474.

81. Horzinek M., Keldermans L., Stuurman T., Black J., Herrewegh A., Sillekens P. \& Koolen M. (1991) - Bovine immunodeficiency virus: immunochemical characterization and serological survey. J. gen. Virol., 72, 2923-2928.

82. Jeffrey M. \& Wilesmith J.W. (1992). - Idiopathic brainstem neuronal chromatolysis and hippocampal sclerosis: a novel encephalopathy in clinically suspect cases of bovine spongiform encephalopathy. Vet. Rec., 131, 359-362.

83. Jeffrey M., Simmons M.M. \& Wells G.A.H. (1994). Observations on the differential diagnosis of bovine spongiform encephalopathy in Britain. In Transmissible spongiform encephalopathies. Proceedings of a consultation on BSE with the Scientific Veterinary Committee of the Commission of the European Communities, 14-15 septembre 1993 (R. Bradley \& B. Marchant, édit.). Commission européenne, Bruxelles, 347-358.

84. Johnstone A.C. (1993). - Hepatic encephalopathy and bovine spongiform encephalopathy. Surveillance, 20, 28.

85. Kimberlin R.H. (1992). - Encéphalopathie spongiforme bovine. In Encéphalopathies spongiformes transmissibles des animaux (R. Bradley \& D. Matthews, édit.). Rev. sci. tech. Off. int. Epiz., 11 (2), 391-439.

86. Kirkwood J.K. \& Cunningham A.A. (1994). Epidemiological observations on spongiform encephalopathies in captive wild animals in the British Isles. Vet. Rec., 135, 296-303.

87. Kiupel H. \& Wehr J. (1980). - Zum Vorkommen der sporadischen bovinen Enzephalomyelitis (SBE) im Norden der DDR. Wiss. Zeitschr. Humboldt Univ. Berlin, Math. nat. R, 29, 57-59.

88. Kopcha M. (1987). - Nutritional and metabolic diseases involving the nervous system. Vet. Clin. N. Am. (Food Anim. Pract.), 3, 119-135.

89. Kronfeld D.S. (1974). - Les troubles métaboliques. In Médecine et chirurgie des bovins [Traduction de «Bovine medicine and surgery »]. Vigot Frères, Paris, $387-454$

90. Le Bars J. \& Le Bars P. (1996). - Recent acute and subacute mycotoxicoses recognized in France. Vet. Res., 27, 383-394.

91. Leipold H.W. \& Dennis S.M. (1987). - Congenital defects of the bovine central nervous system. Vet. Clin. N. Am. (Food Anim. Pract.), 3, 159-177.

92. Leupold U., Martig J. \& Vandevelde M. (1989). - Diagnostic aspects of neurological diseases of cattle. A retrospective study. Schweiz. Arch. Tierheilkd., 131, 327-340.

93. Liegeois F. (1933). - Traité de pathologie médicale des animaux domestiques. Duculot, Gembloux, 725 pp.

94. Lopez T.A., Campero C.M., Chayer R. \& De Hoyos M. (1997). - Ergotism and photosensitization in swine produced by the combined ingestion of Claviceps purpurea sclerotia and Ammi majus seeds. J. vet. diagn. Invest., 9, 68-71.

95. Lorgue G., Lechenet J. \& Rivière A. (1987). - Précis de toxicologie clinique vétérinaire. Point Vétérinaire, MaisonsAlfort, 208 pp.

96. Ludwig H. \& Bode L. (2000). - Borna disease virus: new aspects on infection, disease, diagnosis and epidemiology. In Le point sur les zoonoses (P.-P. Pastoret, édit.). Rev. sci. tech. Off. int. Epiz., 19 (1), 259-288. 
97. McCoy M.A., Young P.B., Edgar H.W., McCarville E.M., Davison G., Fitzpatrick D.A. \& Kennedy D.G. (2002). Biochemical changes induced by hypomagnesemia in lactating cows and ewes. Vet. Rec., 150, 176-181.

98. McElroy M.C. \& Weavers E.D. (2001). - Clinical presentation of bovine spongiform encephalopathy in Republic of Ireland. Vet. Rec., 149, 747-748.

99. McGill I.S. \& Wells G.A. (1993). - Neuropathological findings in cattle with clinically suspect but histologically unconfirmed bovine spongiform encephalopathy (BSE). J. comp. Pathol., 108, 241-260.

100. Manteca C., Daube G., Jauniaux T., Limbourg B., Kaeckenbeeck A. \& Mainil J.G. (2000). - Étude de l'entérotoxémie bovine en Belgique. II. Épizootiologie élémentaire et pathologie descriptive. Ann. Méd. vét., 145, 75-82.

101. Martens H. \& Schweigel M. (2000). - Pathophysiology of grass tetany and other hypomagnesemias. Vet. Clin. N. Am. (Food Anim. Pract.), 16, 339-368.

102. Matthias D. (1954). - Der Nachweis von latent infizierten Pferden, Schafen und Rindern und deren Bedeutung als Virusreservoir bei der Bornaschen Krankheit. Arch. experim. VetMed., 8, 506-511.

103. Mayhew I.G. (1989). - Evaluation of the large animal neurologic patient. In Large animal neurology. A handbook for veterinary clinicians. Lea \& Febiger, Philadelphie, Londres, 3-69.

104. Meyer G., D’Offay J. \& Thiry E. (2000). - Les encéphalites à herpèsvirus bovins. Point vét., 31, 417-424.

105. Millemann Y., Remy D. \& Brugère-Picoux J. (2000). - La listériose des ruminants. 1 : Étiologie, pathogénie et épidemiologie. Point. Vét., 31, 313-316.

106. Morgan S.E. \& Edwards W.C. (1986). - Bovine bonkers: new terminology for an old problem. A review of toxicity problems associated with ammoniated feeds. Vet. hum. Toxicol., 28, 16-18.

107. Morignat E., Ducrot C., Roy P., Baron T., Vinard J.-L., Biacabe A.-G., Madec J.-Y., Bencsik A., Debeer S., Eliazsewicz M. \& Calavas D. (2002). - Targeted surveillance to assess the prevalence of BSE in high-risk populations in western France and the associated risk factors. Vet. Rec., 151, 73-77.

108. Moynagh J. \& Schimmel H. (1999). - Tests for BSE evaluated. Bovine spongiform encephalopathy. Nature, 400, 105.

109. Msolla P., Semuguruka W.D., Kasubu A.A. \& Shoo M.K. (1993). - Clinical observations on bovine parasitic otitis in Tanzania. Trop. anim. Hlth Prod., 25, 15-18.
110. Okamoto M., Furuoka H., Hagiwara K., Kamitani W., Kirisawa R., Ikuta K. \& Taniyama H. (2002). - Borna disease in a heifer in Japan. Vet. Rec., 150, 16-18.

111. Oliver J.E., Lorenz M.D. \& Kornegay J.N. (1997). Handbook of veterinary neurology, $3^{e}$ éd. W.B. Saunders, Philadelphie, 463 pp.

112. Organisation mondiale de la santé (OMS) (2001). - Rabies surveillance report. Center for Rabies Surveillance and Research. Rabies Bull. Eur., 3, 4-8.

113. Oyster R., Leipold H.W., Troyer D., Cash W. \& Johnson D. (1992). - Histochemical and morphometric studies of peripheral muscle in bovine progressive degenerative myeloencephalopathy of brown Swiss cattle. Zentralbl. Veterinärmed., A, 39, 321-327.

114. Pastoret P.-P., Brochier B., Vandeputte J., Chappuis G., Desmettre P., Lombard M. \& Lardy C. (2001). - In Memoriam : Charles Mérieux. Une vie dans la continuité de Pasteur. Ann. Méd. vét., 145, 59

115. Pastoret P.-P., Gouffaux M., Saegerman C., Roels S., Dechamps P., Thiry E. \& Vanopdenbosch E. (2001). - Le diagnostic immunologique rapide des encéphalopathies spongiformes transmissibles. Ann. Méd. vét., 145, 164-173.

116. Perdok H.B. \& Leng R.A. (1987). - Hyperexcitability in cattle fed ammoniated roughages. Anim. Feed Sci. Technol., 17, 121-143.

117. Plumlee K.H. \& Galey F.D. (1994). - Neurotoxic mycotoxins: a review of fungal toxins that cause neurological disease in large animals. J. vet. internal Med., 8, 49-54.

118. Polack B., Schwartz I., Berthelemy M., Belloc C., Manet G., Vuillaume A., Baron T., Gonda M.A. \& Levy D. (1996). Serologic evidence for bovine immunodeficiency virus infection in France. Vet. Microbiol., 48, 165-173.

119. Power E.P., O'Connor M., Donnely W.J. \& Dolan C.E. (1990). - Aujeszky's disease in a cow. Vet. Rec., 126, 226

120. Pranter M.M. \& Sosalla M.J. (1993). - Delayed organophosphate neurotoxicosis in four heifers. J. Am. vet. med. Assoc., 203, 1453-1455.

121. Rice D.A., McMurray C.H. \& Davidson J.F. (1983). - Ketosis in dairy cows caused by low levels of lincomycin in concentrate feed. Vet. Rec., 113, 495.

122. Roels S., Charlier G., Letellier G., Leyer G., Schnynts F., Kerkhofs P., Thiry E. \& Vanopdenbosch E. (2000). - Natural case of bovine herpesvirus 1 meningoencephalitis in an adult cow. Vet. Rec., 146, 586-588.

123. Rosenberger G. (1976). - Système nerveux central. In Examen clinique des bovins. Point Vétérinaire, MaisonsAlfort, 460-469. 
124. Saegerman C., Claes L., Vanopdenbosch E., Biront P., Deluyker H. \& Thiry E. (1999). - Étude rétrospective de l'incidence des troubles neurologiques rapportés et suspects d'encéphalopathie spongiforme transmissible chez les bovins en Belgique. Épidémiol. Santé anim., 35, 31-42.

125. Saegerman C., Dechamps P., Vanopdenbosch E., Roels S., Petroff K., Dufey J., Van Caeneghem G., Devreese D., Varewyck H., De Craemere H., Desmedt I., Cormann A., Torck G., Hallet L., Hamerijckx M., Leemans M., Vandersanden A., Peharpre D., Brochier B., Costy F., Muller P., Thiry E. \& Pastoret P.-P. (1999). Épidémiosurveillance de l'encéphalopathie spongiforme bovine en Belgique: bilan de l'année 1998. Ann. Méd. vét., 143, 423-436.

126. Saegerman C., Dechamps P., Roels S., Petroff K., Geeroms R., Torck G., Dufey J., Fourez R., Hamelryckx M., Cormann A., Viatour P., De Conninck V., Lomba F., Vermeersch J.-P., Hallet L., Lhost O., Leemans M., Vandersanden A., Peharpre D., Brochier B., Costy F., Pastoret P.-P., Thiry E. \& Vanopdenbosh E. (2001). - Épidémiosurveillance de l'encéphalopathie spongiforme bovine en Belgique : bilan de l'année 1999. Ann. Méd. vét., 145, 47-58.

127. Schelcher F., Foucras G., Meyer G., Andreoletti O. \& Valarcher J.-F. (2001). - Le coryza gangréneux chez les bovins. Point vét., 215, 30-35.

128. Schelcher F., Andreoletti O., Cabanie P. \& Tabouret G. (2001). - Démarche diagnostique dans les maladies nerveuses des bovins. In Actualités en buiatrie. Journées européennes, Société française de buiatrie (SFB), 2830 novembre, Paris. SFB, Toulouse, 229-240.

129. Schillhorn van Veen T.W. (1987). - Parasitic disease of the bovine nervous system. Vet. Clin. N. Am. (Food Anim. Pract.), 3, 99-105.

130. Schlech W.F. (1991). - Listeriosis epidemiology, virulence and the significance of contaminated foodstuffs. J. Hosp. Infect., 19, 211-224.

131. Schreuder B.E. \& Osterhaus A.D. (1990). - Bovine spongiform encephalopathy (BSE), a review. Tijdschr. Diergeneeskd., 115, 507-517.

132. Scobie L., Venables C., Sayers A.R., Weightman S. \& Jarrett O. (2001). - Prevalence of bovine immunodeficiency virus infection in cattle in Great Britain. Vet. Rec., 149, 459-460.

133. Sherman D.M. (1987). - The role of clinical examination in the accurate diagnosis of bovine neurologic disease. Vet. Clin. N. Am. (Food Anim. Pract.), 3, 1-12.

134. Sherman D.M. (1987). - Localized diseases of the bovine brain and spinal cord. Vet. Clin. N. Am. (Food Anim. Pract.), 3, 179-191.
135. Snider T.G., Hoyt P.G., Jenny B.F., Coats K.S., Luther D.G., Storts R.W., Battles J.K. \& Gonda M.A. (1997). - Natural and experimental bovine immunodeficiency virus infection in cattle. Vet. Clin. N. Am. (Food Anim. Pract.), 13, 151-176.

136. Stöber M. (1987). - Symptomatologie différentielle de quelques affections du système nerveux des bovins. Ann. Méd. vét., 131, 401-410.

137. Stowe C.M. (1997). - Central nervous system intoxications other than lead. Vet. Clin. N. Am. (Food Anim. Pract.), 13, 149-158.

138. Tenhumberg H., Trela T., Matzke P., Averdunk G. \& Dirksen G. (1994). - Bovine progressive degenerative myeloencephalopathy ('Weaver syndrome') in Brown Swiss $\times$ Braunvieh cattle: reproductive features and embryo transfer. Berl. Münch. tierärztl. Wochenschr., 107, 400-404

139. Thiry E. (2000). - Maladies virales des ruminants. Point Vétérinaire, Maisons-Alfort, 244 pp

140. Tsuji M., Terada Y., Arai S., Okada H. \& Ishihara C. (1995). - Use of the Bo-RBC-SCID mouse model for isolation of a Babesia parasite from grazing calves in Japan. Experim. Parasitol., 81, 512-518.

141. Tvedten H.W. (1987). - Clinical pathology of bovine neurologic disease. Vet. Clin. N. Am. (Food Anim. Pract.), 3, $25-44$

142. Underwood W.J. (1992). - Rumen lactic acidosis. Part II. Clinical signs, diagnosis, treatment and prevention. Compend. cont. Educ. pract. Vet., 14, 1265-1270.

143. Valdes J.J., Cameron J.E. \& Cole R.J. (1985). - Aflatrem: a tremorgenic mycotoxin with acute neurotoxic effects. Environ. Hlth Perspect., 62, 459-463.

144. Vallet A. (2000). - Les autres maladies infectieuses provoquant des troubles nerveux. In Maladies des bovins (Institut de l'élevage, dir.). France Agricole, Paris, 84-85.

145. Vallet A. (2000). - La myopathie dyspnée. In Maladies des bovins (Institut de l'élevage, dir.). France Agricole, Paris, 234-235.

146. Vallet A. (2000). - La nécrose du cortex cérébral. In Maladies des bovins (Institut de l'élevage, dir.). France Agricole, Paris, 236-237.

147. Van Cauteren H., Vandenberghe J., Herin V., Vanparys P. \& Marsboom R. (1985). - Toxicological properties of closantel. Drug. chem. Toxicol., 8, 101-123.

148. Vancutsem P.M., Babish J.G. \& Schwark W.S. (1990). - The fluoroquinolone antimicrobials: structure, antimicrobial activity, pharmacokinetics, clinical use in domestic animals and toxicity. Cornell Vet., 80, 173-186. 
149. Vandevelde M., Zurbriggen A. \& Fatzer R. (1992). Spongiform encephalopathies with special reference to bovine spongiform encephalopathy. Schweizer. Med. Wochenschr., 122, 887-892.

150. Vanopdenbosch E., Dechamps P., Saegerman C., Dufey J., Roels S.T., Mullier P., Hallet L., Brochier B., Costy F., Charlier G., Fourez R. \& Pastoret P.-P. (1998). - Le premier cas d'encéphalopathie spongiforme bovine diagnostiqué en Belgique. Ann. Méd. vét., 142, 111-118.

151. Voros K., Tanyi J. \& Karsai F. (1999). - Clinical experiences with rabies in cattle in Hungary. Dtsch. tierärztl. Wochenschr. $106,46-48$

152. Walder R., Kalvatchev Z., Tobin G.J., Barrios M.N., Garzaro D.J. \& Gonda M.A. (1995). - Possible role of bovine immunodeficiency virus in bovine paraplegic syndrome: evidence from immunochemical, virological and seroprevalence studies. Res. Virol., 146, 313-323.

153. Wells G.A.H., Scott A.C., Johnson C.T., Gunning R.F., Hancock R.D., Jeffrey M., Dawson M. \& Bradley R. (1987). - A novel progressive spongiform encephalopathy in cattle. Vet. Rec., 121, 419-420.

154. Wells G.A.H., Sayers A.R. \& Wilesmith J.W. (1995). Clinical and epidemiological correlates of the neurohistology of cases of histologically unconfirmed, clinically suspect bovine spongiform encephalopathy. Vet. Rec., 136, 211-216.

155. White M.E. (2002). - Consultant. A diagnostic support system for veterinary medicine. Cornell College of Veterinary Medecine. (www.vet.cornell.edu/consultant/ consult.asp, consulté le 13 décembre 2002).

156. Wilesmith J.W. (1998). - Manual on bovine spongiform encephalopathy. Organisation des Nations Unies pour l'alimentation et l'agriculture, Rome, $51 \mathrm{pp}$.
157. Wilesmith J.W., Wells G.A., Cranwell M.P. \& Ryan J.B. (1988). - Bovine spongiform encephalopathy: epidemiological studies. Vet. Rec., 123, 638-644.

158. Will R.G., Ironside J.W., Zeidler M., Cousens S.N., Estibeiro K., Alperovitch A., Poser S., Pocchiari M., Hofman A. \& Smith P.G. (1996). - A new variant of Creutzfeldt-Jakob disease in the UK. Lancet, 347, 921-925.

159. Wilson B.J., Byerly C.S. \& Burka L.T. (1981). - Neurologic disease of fungal origin in three herds of cattle. J. Am. vet. med. Assoc., 179, 480-481.

160. Wittmann G. (1989). - Aujeszky's disease in ruminants. In Herpesvirus disease of cattle, horses and pigs (G. Wittmann, édit.). Developments in Veterinary Virology, Kluwer Academic Publishers, Boston, 163-175.

161. Yamada M., Nabagawa M., Yamamoto M., Furuoka H., Matsui T. \& Taniyama H. (1998). - Histopathological and immunohistochemical studies of intracranial nervous-system tumours in four cattle. J. comp. Pathol., 119, 75-82.

162. Zeidler M. \& Ironside J.W. (2000). - The new variant of Creutzfeldt-Jakob disease. In Le point sur les zoonoses (P.-P. Pastoret, édit.). Rev. sci. tech. Off. int. Epiz., 19 (1), 98120.

163. Zwich W. \& Witte J. (1932). - Zur Frage der Schutzimpfung und der Inkubationsfrist bei der Bornaschen Krankheit. Arch. Tierheilkd., 64, 116-124. 